\title{
واقع استخدام معلمات اللغة العربية للمرحلة الابتدائية لاستراتيجيات التعلم الممتع بمدينة الرياض
} وفاء بنت عايض سعد الحارثي

أستاذ مساعد بكلية التربية جامعة الأمير سطام بن عبد العزيز

\section{المستخلص:}

هدفت الدراسة الحالية إلى معرفة واقع استخدام معلمات اللغة العربية بالمرحلة

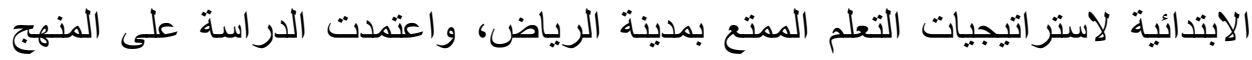

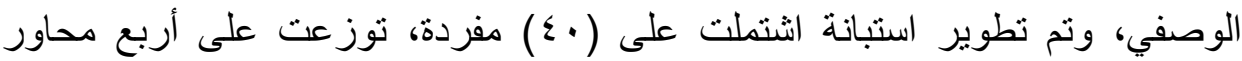

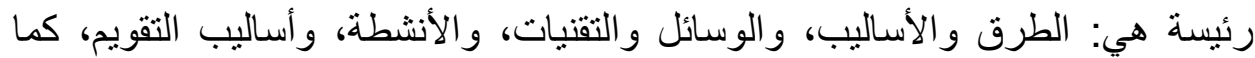

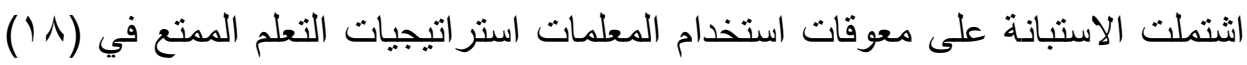

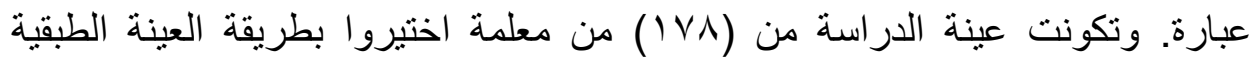
العشوائية. وقد أظهرت نتائج الدراسة أن معلمات اللغة العربية بالمرحلة الابندائية يستخدمن استر اتيجيات التعلم الممتع بدرجة متوسطة بشت التكل عام، و أن مو افقة أفراد العينة

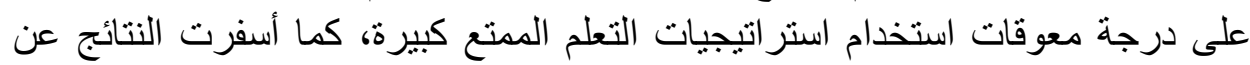

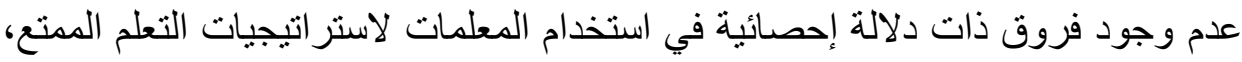

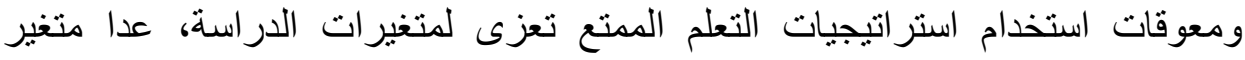

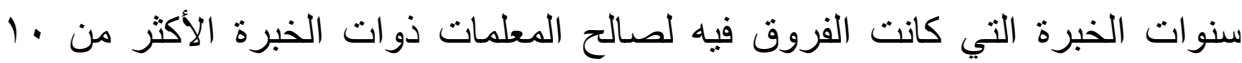

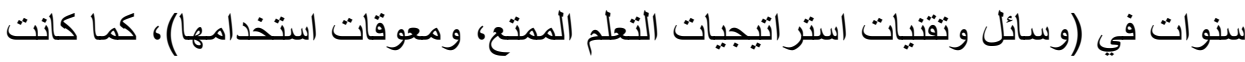

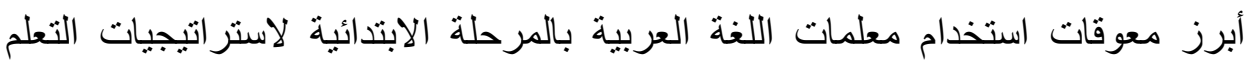

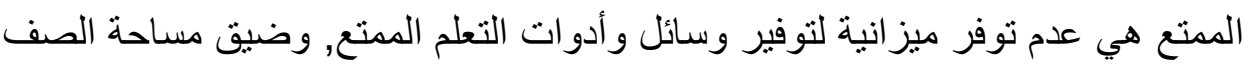

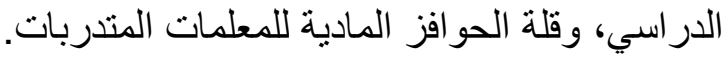

الكلمات المفتاحية: التعلم الممتع، معلمات اللغة العربية، المرحلة الابتدائية، استر اتيجيات التعلم. 


\section{واقع استخدام معلمات اللغة العزبية للمرحلة الابتدائية لاستراتيجيات التعلم المتع بمدينة الرياض}

\section{Abstract:}

The current study aimed to reveal the degree of which Arabic language teachers at the elementary level use enjoyable learning strategies in Riyadh. The study applied the descriptive approach and developed a questionnaire that included (40) items, which was divided into these four main axes: methods, means and techniques, activities, and evaluation methods; the questionnaire also included the obstacles of using enjoyable learning strategies in (18) items. The study sample consisted of (178) teachers that were chosen randomly. The study results showed that Arabic language teachers at the elementary level generally use enjoyable learning strategies with a medium degree, and that the study samples' agreement came to a high level on the obstacles of using the enjoyable learning strategies; also, the results showed that there were no statistically significant differences in the teachers' use of enjoyable learning strategies, as well as the obstacles of using enjoyable learning strategies due to the study variables, except for years of experience variable in which the differences were in favor of teachers with more than 10 years of experience in (means and techniques of enjoyable learning strategies, and obstacles of using enjoyable learning strategies). The most prominent obstacles of using enjoyable learning strategies among Arabic language teachers were: the lack of a budget to provide the means and tools for enjoyable learning, and the limited classroom space, and the lack of incentives for the training teachers.

Key words: enjoyable learning, Arabic language teachers, elementary school, learning strategies. 
أ.م.د/ وفاء بنت عايض سعد الحارثي

\section{واقع استخدام معلمات اللغة العربية للمرحلة الابتدائية \\ لاستراتيجيات التعلم الممتع بمدينة الرياض}

وفاء بنت عايض سعد الحارثي

أستاذ مساعد بكلية التربية جامعة الأمير سطام بن عبد العزيز

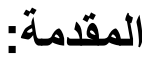

تؤكد التوجهات التربوية المعاصرة على أهمية التوجه نحو التعلم الممتع، فيبين

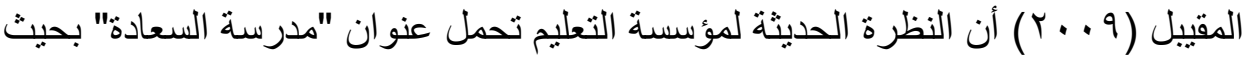
يصبح الهذف الرئيس للمدرسة هو إسعاد المتعلم عند تعليمه وتهذييه، كما يثير محمود

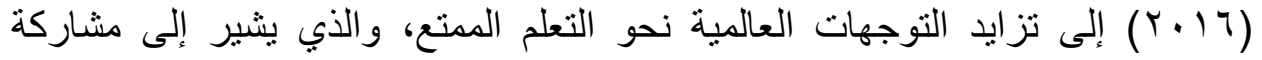

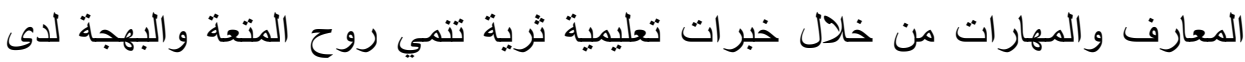
المتعلمين والتي يتم التخطيط لها بشكل منضبط يوازن بين تحقيق الأهداف الأكاديمية

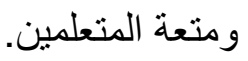

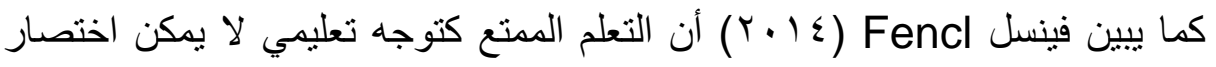

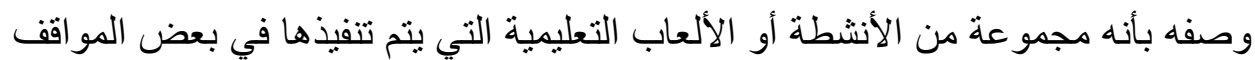
التعليمية، بل إنه أشمل من ذلك، فهو يحول الموقف التعليمي بكل عناصره ومضمونه التعليمي بصورة منضبطة ومتناسقة إلى خبر ات تعليمية مرنة وممتعة يثارك الطالب في تحديد مكوناتها، وفي ذات الصدد يشير سشاتتير Schattner (10 ب ب) إلى أن التعلم المنع هو عمل استراتيجي يهدف إلى تطوير الموقف التعليمي بصورة دقيقة من خلال

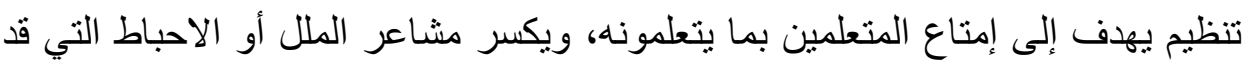
تصاحب المواد التعليمية ذات الطبيعة الأكاديمية القائمة على الاستدلال والمنطق. ولانا

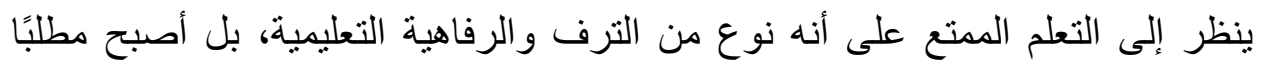


واقع استخدام معلمات اللغة العربية للمرحلة الابتدائية لاستراتيجيات التعلم الممتع بمدينة الرياض

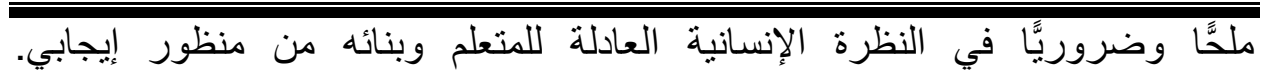

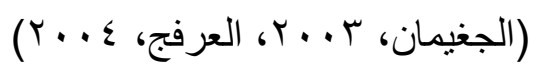

ويسهم التعلم الممتع في تحفيز المتعلمين و إثارة دافعيتهم وتركيز هم واهتمامهم، وير افق التعلم الممتع غالبًا أحاسيسًا إيجابية بمستو معتدل كالسعادة و السرور و البهجة التي تسبب وهيب لهم أحيانًا الابتسام والضحك اللذين يساعدان على زيادة تدفق الدم في مختلف أنحاء الجسم، وتدفقًا للأكسجين إلى الدماغ بشكل صحي وموثر على التعلم، وبسبب الأحاسيس الإيجابية المر افقة للتعلم الممتع يكون لدى المتعلمين قدرة أعلى على التركيز و التفكير

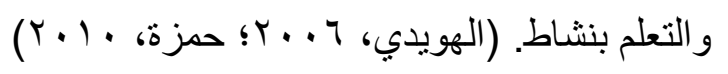

ويعد التعلم الممتع متضمنًا في معظم استراتيجيات التدريس الحديثة عندما تتوفر ظروف الاستمتاع فيها، كالتعلم باللعب والتعلم النشط و التعلم التعاوني و التعلم بالقصص و الدر اما وتمثيل الأدوار، و التعليم الإلكتروني، والتعلم بالمسابقات. ويعتمد التطبيق الفعلي لاستراتيجيات التعلم المتع على المعلمين، فيوضح السويدان

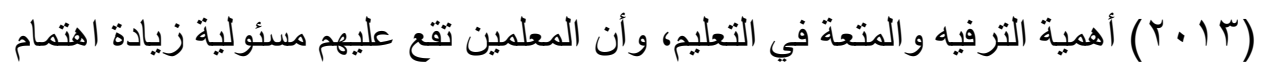
المتعلمين بتعلمهم والحفاظ عليه في درجات عالية ما أمكن، وتوفير ظروف التعلم الممتع، و هذا يتطلب من المعلمين أنفسهم الإبقاء على حماسهم الذاتي ودافعيتهم ودرجة استمتاعهم الثخصي في أعلى مستويات ممكنة في أثناء التعليه. يو اجه بعض المعلمين صعوبة في تطبيق التعلم الممتع بسبب اعتقاداتهم نحوه، كطبيعة اللغة المجردة التي يصعب تدريسها بطريقة ممتعة، وكم المنهاج مع ضيق الوقت، وكثرة أعداد المتعلمين في الصف الواحد، وصعوبة المحافظة على النظام أثناء أنشطة التعلم المرح، مع تتفاوت هذه الاعتقادات بين المعلمين. 
أ.م.د/ وفاء بنت عايض سعد الحارثي

ويثير Anggoro, et al

تضافر العديد من الأجهزة الحسية أثناء عمليات التعلم حيث أظهرت العديد من الأدبيات

أن أنشطة التعلم الممتعة تعطي نتائج إيجابية تعود بالنفع على المعلم والمتعلم معًا.

وقد أثتتت البحوث و الدراسات السابقة فاعلية التعلم الممتع في تعلم اللغة، مثل: در اسة

(رامبلي وآخرون .Rambli, et al) با •r)، ودراسة (خبر الله وروحمي

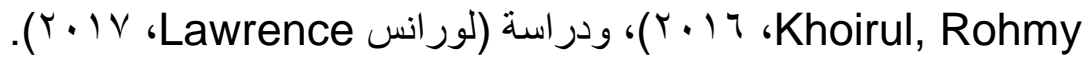

\section{مثكلة الار اسة:}

تتحدد مشكلة الدراسة في ضعف الطلاب في مهارات اللغة العربية والتي أرجعتها معظم الدراسات إلى أسباب متعددة من ضمنها إسهام معلمي اللغة العربية ومعلماتها في تعقيد مادة اللغة العربية في أثناء تدريسهم لها، وتخلف الوسائل و الأساليب المستخدمة في تدريسها، وعدم شعور الطلاب بالمتعة والفائدة من تدريسها، مما يجعلهم يعزفون عن در استها، ومن ثم يسهم في ضعفها على ألسنتهم، وفي كتابتهم وتعبير هم بها. (النصار،

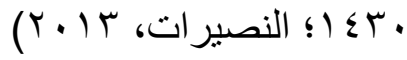

وقد لاحظت الباحثة من خلال إثرافها على طالبات التربية الميدانية عزوف الطالبات عن تعلم اللغة العربية، يظهر ذلك في تدني مستوياتهن وقلة دافعيتهن للتعلم، ومن خلال حضور الباحثة مع الطالبات المعلمات حصص المشاهدة لمعلمات اللغة العربية وجدت أن أعدادا قليلة من المعلمات اللاتي يستخدمن أساليب تثير دافعية الطالبات للتعلم، وأنه ما زالت أساليب ووسائل تعليم اللغة العربية لا تتمانشى مع التطورات والمستجدات في الميدان التربوي، ونزولًا عند نوصيات الدراسات السابقة

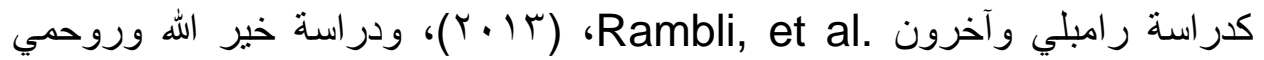
Khorual \& Rohmy اللغة، ولعدم وجود دراسة محلية - في حدود علم الباحثة- تناولت التعلم الممتع في 
واقع استخام معلمات اللغة العربية للمرحلة الابتدائية لاستراتيجيات التعلم الممتع بمدينة الرياض

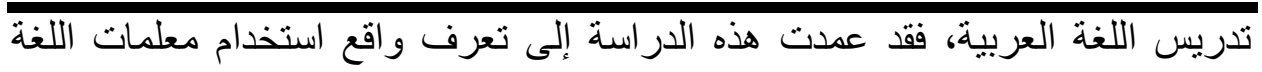
العربية بالمرحلة الابتدائية لاستر اتيجيات التعلم المدتع.

وللتصدي لهذه المشكلة حاولت الدر اسة الحالية الإجابة عن الأسئلة الآثية:

ا . ما واقع استخدام معلمات اللغة العربية بالمرحلة الابتدائية لاستر اتيجيات التعلم المتع

(الطرق و الأساليب، الأنشطة، الوسائل و التقنيات، أساليب التقويم)؟

Y. ما معوقات استخدام معلمات اللغة العربية بالمرحلة الابتدائية لاستر اتيجيات التعلم

المثنع؟

r. هل توجد فروق ذات دلالة إحصائية عند مستوى (0., ·) في درجة استخدام

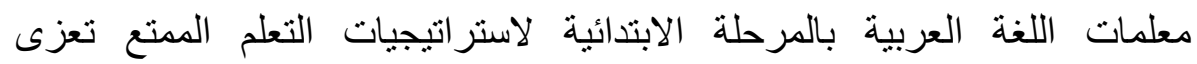
للمتغيرات الآتية (العمر، عدد سنوات الخبرة، والمؤهل العلمي، وعدد الدورات التدريبية)؟

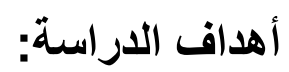

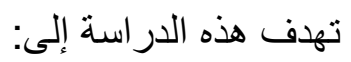

1. تعرف واقع استخدام معلمات اللغة العربية بالمرحلة الابتدائية لاستراتيجيات التعلم

الممتع (الطرق و الأساليب، الأنشطة، الوسائل و التقنيات، أساليب التقويم).

r. تعرف معوقات استخدام معلمات اللغة العربية بالمرحلة الابتدائية لاستراتيجيات

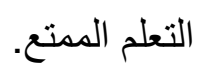

r. الكثف عن مدى وجود فروق ذات دلالة إحصائية في درجة استخدام معلمات اللغة

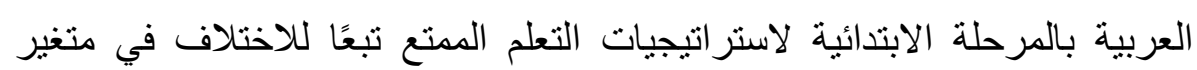

(العمر، و المؤهل العلمي، وعدد سنوات الخبرة، وعدد الدورات التدريبية).

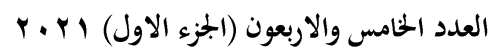

(154)

مجلة كلية التربية- جامعة عين شمس 
قد تسهم هذه الدر اسة فيما يأني:

ا. إفادة معلمات اللغة العربية باستراتيجيات التعلم الممتع، وتوجيه اهتمامهم نحو

استخدامها، وتوظيفها في تحسين العملية التعليمية، وأبرز المعوقات التي تحول دون

استخدامها.

Y. تقديم أداة بحثية مقننة لقياس واقع استخدام باستر اتيجيات التعلم الممتع في التعليم، والمعوقات التي تحول دون استخدامها؛ حيث يمكن أن بستفيد منها الباحثون في

در اسات مشابهة.

r. توجيه نظر القائمين على عملية تطوير المناهج لتضمين استراتيجيات التعلم الممتع في تدريس مهار ات اللغة العربية في مقرر لغتي الخالدة.

ء. فتح المجال أمام دراسات أخرى في استخدام استراتيجيات التعلم الممتع في تعليم اللغة العربية، في مختلف مر احل التعليم.

حدود الدراسة:

- الحدود المكانية: اقتصرت الدر اسة على المدارس الحكومية للمرحلة الابتدائية للبنات بمدينة الرياض، باعتبار أن المدارس الأهلية يفترض أنها توفر الكثير من التقتيات التي تساعد على استخدام استراتيجيات التعلم الممتع.

- الحدود الزمنية: طبقت الدراسة خلال الفصل الثاني من العام الدراسي ( (ع ا ه). مصطحات الدراسة:

المرحلة الابتدائية: وهي تمثل الصفوف الأولى من المراحل الدراسية في نظام التعليم في المملكة العربية السعودية، وتمتد من الصف الأول إلى الصف السادس. 
واقع استخدام معلمات اللغة العربية للمرحلة الابتدائية لاستراتيجيات التعلم المتعع بمدينة الرياض

وتعرف إجرائيا أنها: هي المرحلة التي سبطبق على معلمات اللغة العربية بها أداة الدر اسة وهي استبانة تهدف لتعرف واقع استخدام معلمات اللغة العربية لاستر اتيجيات التعلم الممتع. الاستراتيجية: وهي "مجموعة الطرائق والإجراءات والنشاطات والوسائل التي يستخدمها المعلم لتحقيق أهداف التعلم وهي مكونة من خطة إعداد الدرس ودور المعلم

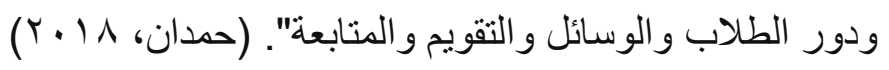

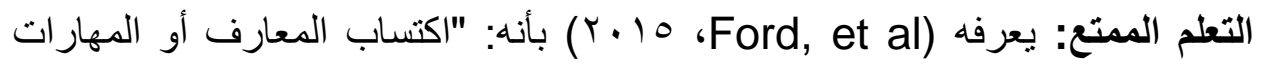
بالطرق التي تحقق لأطفال المرحلة الابتدائية المتعة والسعادة، من خلال زيادة دافعيتهم ومشاركتهم وانتباههم في عمليات التعلم، وتعزز الجوانب الوجدانية في التعلم مما يؤثر إيجابيًّا في الجو انب المعرفية للأطفال".

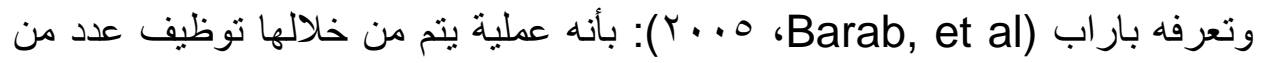
الاستر اتيجيات كاللعب، والأنشطة، و المشروع، وتوظيف بيئات تعلم افتراضية، و إتاحة فرصة للطلاب للعمل في بيئات تعلم تعاونية مما يساعد في الدمج بين عملية التعلم و الترفيه و التو اصل الاجتماعي. وتعرف الباحثة استراتيجيات التعلم الممتع إجرائيًا بأنها: كل استراتيجية تستخدمها معلمة اللغة العربية للمرحلة الابتدائية، وتوفر جوَّا من البهجة والمتعة والتسلية الهادفة للتلميذة، والتي تجعل الدماغ يعمل في أقصى طاقاته، وتجعل التلميذة تقبل على التعلم بدافعية.

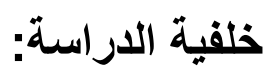

ظهر مفهوم التعلم الممتع للإشارة إلى مشاركة الطلاب في خبرات تعلمهم وتقييمهم وتمتعهم بعملية التعليم في حد ذاتها، حيث يقدم هذا الاتجاه مجموعة من خبرات التعلم 


\section{أ.م.د/ وفاء بنت عايض سعد الحارثي}

الفريدة والمميزة، والتي سيكون لها انعكاساتها على البحث التربوي المستقبلي وتصميم الخبرات التعليمية.

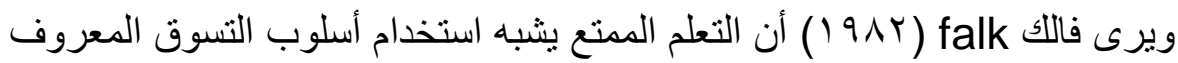
The analogy of a window-shopper ولكن مجرد التمتع بخبرة التسوق، كذلك مصطلح autotelic وهو فعل الثيء لغايته للإشارة إلى نوع من الأنشطة مثل تسلق الصخور، ولعب الثطرنج، والموسيقى، و الرقص، ولعب الرياضة و التي يشعر الفرد نتيجة لممارستها بالإشباع و السعادة.

الأسس النظرية للتعلم الممتع:

فكرة التعليم الممتع لها أفكار شائعة مع عدد من الأسس النظرية المتنوعة والتي

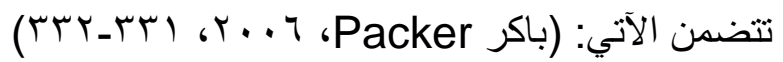

ا. اقتصاد الخبرة The experience economy: إن الخبرات ما هي إلا عروض اقتصادية تتميز عن البضائع والخدمات، فالناس بريدون التأثر بالخبرة، و هم يبحثّن عن الخبرات التي تغيرهم وتغير نظرتهم للعالم وتنمّي قدراتهم ونثير إحساسه بالتعجب والجمال، فليس مجرد تقديم المعلومة هو المهح بالنسبة للطلاب، ولكن الأهم هو الخبرة المحيطة بهذا التقديم.

Y. خبرة التدفق Flow -experience: إن خبرة التدفق Flow تعني الإحساس بالمشاركة التامة في نشاط ما لدرجة نسيان الوقت، أو الإرهاق. وقد سميت تدفقًا لأنها ما هي إلا تيار يجعل المتعلمين مركزين على النشاط، ويمكن أن توجد في أي الي نشاط سواء (اللعب، أو العمل، أو الدراسة، أو الرياضات). و وعلى وجه العموم فإن لهان خبرة التدفق يمكن وصفها على أنها ربط خبرتين ببعضهما البعض، وهما: المتعة و التركيز المكثف، فالمتعلمون يستمتعون بتعلمه وفي ذات الوقت يستغرقون ذهنيًّا فيما بتعلمونه بالفعل. 
واقع استخدام معلمات اللغة العربية للمرحلة الابتدائية لاستراتيجيات التعلم المتع بمدينة الرياض

بَ. المقابل الجمالي The aesthetic encounter: يعد المقابل الجمالي في التعلم الممتع أبرز مخرجات التعلم الممتع بغض النظر عن مدى المخرجات المعرفية، والخبرة الجمالية تتفق في مفهومها مع خبرة التدفق، بل ويوجد من يعتبر المتعة مشتقة من المقابلات الجمالية والتي تفسر على أنها إثباع الحاجة للمعرفة والفهم. ؟. الفضول المعرفي Curiosity: ويرتبط بالأفر اد الذين يكون هدفهم اكتساب معرفة معينة و إثباع فضولهم والتمتع بالعملية نفسها؛ حيث إن المعرفة المكتسبة بهذه الطريقة واسعة وسطحية أكثر من أنها ضيقة وعميقة. ويوضح كذلك أن مثل هذه المعرفة يتم اكتسابها بدون وجود استخدام مسبق من العقل، مما يزيد قدر ات التفكير الإبداعي و الاستجابة للتغيير في البيئة. •. الدافعية الذاتية Intrinsic motivation: يعتمد التعلم الممتع على الدوافع الذاتية، وليس على المكافآت المتوقعة، على خلاف التعليم الرسمي الذي يرتبط عادة بالمكافأة الخارجية كالتقدير ات، و المخرجات الوظيفية.

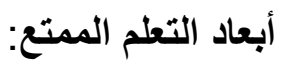
ـ التعلم الممتع يتضمن مزيجًا من الاكتشاف والاستكثاف والإثارة العقلية والتشويق حيث يقدم التعلم الممتع الثعور بالسعادة والرضا، ويكون الفرد أكثر علمًا بإحداث إثارة عقلية واكتشاف أثنياء جديدة، وتوسيع اهتمامات الفرد، كما أن البحث والاكتشاف يقدم تعلمًا أكثر نشاطا عن الخبرات الجديدة والثيقة والمثيرة، ومثل هذه الخبرات هي جوهر التعلم الممتع. ويبقى التعليم و الاكتشاف والمتعة من أهم أسباب و عو امل الإصلاح وتحقيق

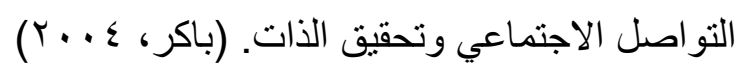
- يقدر الأفراد التعلم الممتع لكونه خبرة تحويلية: فالتعلم المتعلم له دوره في تغيير أسلوب حياتهم ونظرتهم للكون وتتمية قدراتهم الثخصية، فأي تعلم هو تحويلي بطبيعته، وهذا أهم ما يميز الجوانب الانفعالية والمعرفية والتي تعتبر مميزة لبيئة التعليم غير الرسمي. 
أ.م.د/ وفاء بنت عايض سعد الحارثي

ويرى الأفراد أن هذا النوع من التعلم يعزز قدرة الأفراد على التفكير الإبداعي وعلى على لهئ

الاستجابة لأحداث المستقبل غير المعروفة.

ـ غالبية الأفراد يعتبرون التعلم أكثر متعة بو اسطة هذا الأسلوب.

- هذا الأسلوب حقق فاعلية في تشجيع الأفراد على البحث و التعلم.

- هناك أربعة شروط توصيلية في خبرة التعلم الممتع وهي التي تجعل التعلم ممتعًا

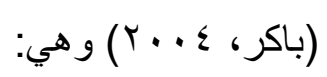

ا . تحقق الاستكثاف والتخيل معًا: إن حدوث التعلم للمتعة يرتبط ارتباطًا وثيقًا بمرور المتعلم بمواقف تعليمية تتطلب درجة مناسبة من استكثاف المعرفة، ولا يكتفى الاسفي

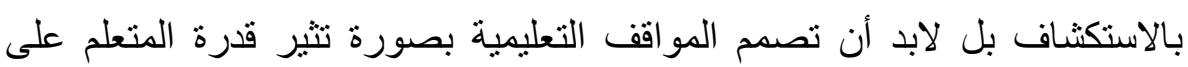

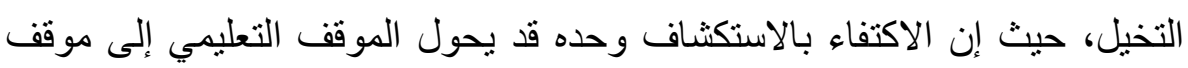
أكاديمي صارم، في حين أن الاستكثاف الممتزج بالتخيل هو الذي يمكن أن يحقق الأنق التعلم للمتعة. r. الخبرة التعليمية متعددة الحواس: يتسم التعلم المثتع بتقديم خبرات تعليمية تخاطب الحواس المختلفة للمتعلم، بحكم طبيعة الإجراءات التي يسلكها المتعلم، ومع تعدد الحواس في الخبرات التعليمية المختلفة فإنه ينوقع اندماج المتعلم الوجداني

$$
\text { و الأكاديمي مع الخبرة التعليمية بدرجة أكبر. }
$$

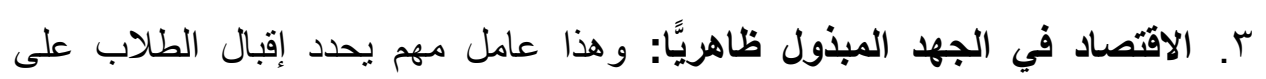

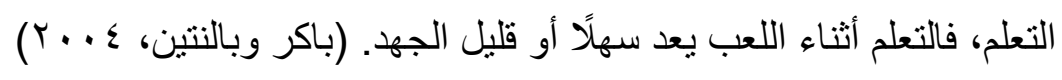

ء. إتاحة فرص الاختيارات: يتسم التعلم الممتع بدرجة كبيرة من المرونة في إعطاء درجة معقولة من حرية وضع واختبار البدائل المختلفة التي تشكل مكونات الخبرة

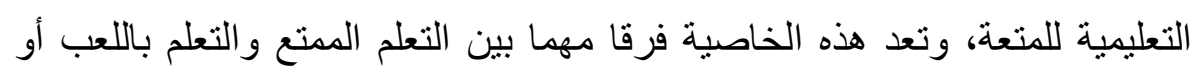

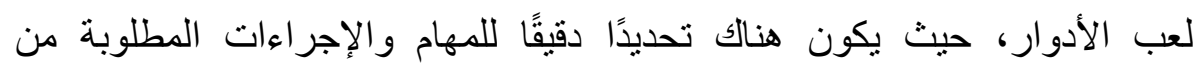
المتعلمين في التعلم باللعب، بينما يتاح للمتعلمين في التعلم الممتع فرصة إضافة دهام

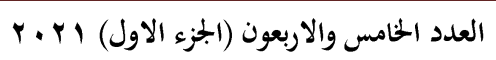


واقع استخدام معلمات اللغة العربية للمرحلة الابتدائية لاستراتيجيات التعلم الممتع بمدينة الرياض

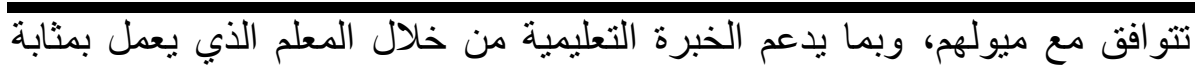

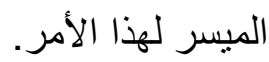

أساليب الوصول للتعلم الممتع:

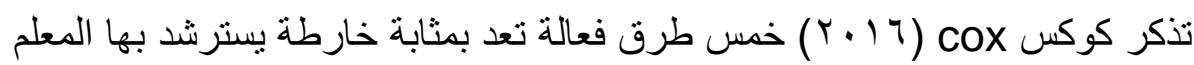
في تدريسه لطلاب المرحلة الابتدائية للوصول للتعلم المتع، وهي: ا. دمج التكنولوجيا في التعليم يساعد المتعلمين على الاستمتاع والانخر اط في التعلم، و على المعلم أن يوظف حبهم للتكنولوجيا؛ لأنهم يجدون المتعة في التعلم عن الن

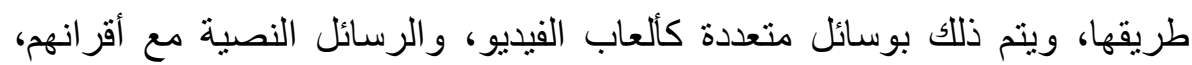
وسماع قصة، ولعبة عن طريق الآيباد، والبحث في الإنترنت. r. بناء بيئة صفية يسودها المرح: وذللك بدمج أنشطة المتعة التعلمية في الدروس، بحيث يشعر جميع المتعلمين بالمتعة في الصف العادي، لذا لابد للمعلم من خلق جو من المتعة في الموضو عات الصعبة حتى يتمكن المتعلمين من الانخر اط في الأنشطة عن طريق اللعب، أو المسابقات، أو الألغاز ، و التدريب العملي عليها. r. تكليف المتعلمين بإجر اء التجارب بأنفسهم لأنهم يجدون المتعة في إجراء التجارب من خلال التعلم بالممارسة، وتعد طريقة مميزة لجعل التعلم أكثر متعة، ولابد أن تكون التجارب بسيطة وممتعة في نفس الوقت. ـ. مراجعة الدروس بصورة مرحة وممتعة مع المتعلمين ليقبلوا على الدرس بشغف ودافعية من خلال عدة استر اتيجيات كالألعاب، و الكرسي الساخن، والمسابقات. ○. الخروج عن الجو التقليدي للصف برحلة أو زيارة لجعل التعلم ممتعًا، كزيارة المتاحف، والمساجد، والحدائق، ويمكن أن يطلب المعلم من المتعلمين رسم ما تعلموه، أو منحهم دقائق للعب على الحاسوب. 
أ.م.د/ وفاء بنت عايض سعد الحارثي

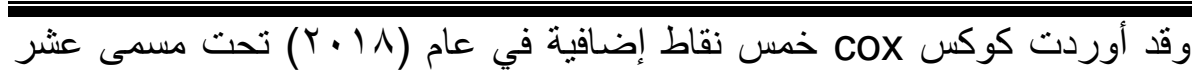
طرق فعالة للتعليم الممتع وهي: T. تكوين فرق عمل ومجموعات تعاونية، حيث أجريت العديد من البحوث التي أكدت أن المتعلمين يحتفظون بالمعلومات بشكل أطول عند استخدام التعلم التعاوني، لأنه يسهم في تتمية مهار ات التفكير الناقد ومهار ات التو اصل. V. إعطاء استراحة للمتعلمين لأن طلاب الابتدائية يعملون بجد طوال اليوم، ولابد لأدمغتهم من استراحة، وقد أظهرت البحوث السابقة أن الطلاب يتعلمون بشكل أفضل عندما يتعرضون لكسر الروتين طوال اليوم الدراسي. ^. إنشاء مر اكز التعلم لأنها تعطي المتعلمين خيارات متعددة للتعلم، وبالتالي تخلق جوَّا من المتعة في التعلم كاستخدام الحاسوب أو الآيباد.

9. تعريف المتعلمين بقدر اتهم وما يمنلكونه من ذكاءات متعددة التي توجه الطريقة التي سيتعلمون بها لمعالجة المعلومات، حيث إن نظرية الذكاءات المتعددة نساعد المعلم

$$
\text { في تعليم الطالب بما يتلاءم مع نمط التعلم لديه. }
$$

• (.وضع قو اعد خاصة بالصف تتيح للطالب الاختيار من بدائل مختلفة. مما سبق يتضح أن للمعلم دور كبير في التخطيط والتنفيذ والتقويم لاستراتيجيات التعلم الممتع في الصف وكيفية إدارة فرق العمل، حيث تتطلب المهارة والخبرة اللازمة لمواعمة هذه الاستر اتيجيات وكيفية استخدامها مع تلاميذ المرحلة الابتدائية، للوصول إلى لى جو يسوده المتعة و الفائدة. دور المعلم في التعلم المتع: تشير نتائج دراسة YlV) Wang أن دور المعلم في التعلم الممتع يقوم على (Y)

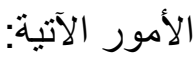
ا. توفير الأساس المنطقي الذي يساعد التلاميذ في فهم مواد التعلم المقدمة، بهدف مساعدتهم على استيعابها، وكذلك مساعدتهم في تعديل تصور اتهم تجاه أنشطة التعلم. 
واقع استخدام معلمات اللغة العربية للمرحلة الابتدائية لاستراتيجيات التعلم المتع بمدينة الرياض

r. استخدام لغة غير مسيطرة تعطي التلاميذ الاستقلالية للقيام بالأنشطة، كذلك القيام بعملية التواصل، وتقديم التغذية الراجعة لهم، و العمل على زيادة الدافعية لديهه، وتعزيز مشاركتهم في ممارسة الأنشطة.

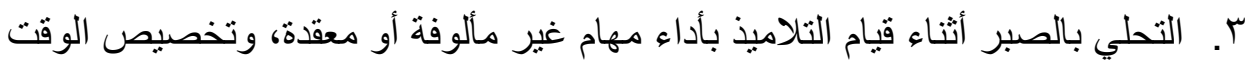
الكافي للاستماع للتنلاميذ، وتقديم التشجيع المستمر لهم، وتقديم التلميحات الهادفة و الموجهة، وتأجيل تقديم النصح والإرشاد لهم حتى يفهم وجهة نظرهم أولاً، وتقديم الدعم و المساندة عند الحاجة.

ع. أن يكون منفتحًا ولديه القدرة على تقبل أخطاء التلاميذ، وأن يكون لديه طريقة في التعامل مع التلاميذ غير المشاركين في الأنشطة. ○. أن بعمل على تعزيز مصادر الدوافع الداخلية لدى التلاميذ، وهذا يتطلب منه البحث عن الطرق التي تسهم في تعزيز وتتسيق الأنشطة التعليمية بحيث تكون مهمة ومفضلة بالنسبة للتلاميذ، وتشعر هم بالقدرة على التحدي، وتوفر لهم الاختيار من

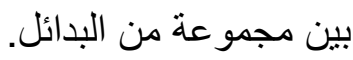
و هناك عدد قليل من الدراسات السابقة التي تطرقت لموضوع الدراسة في تخصصات مختلفة، وهي كالنحو الآتي : أجرى لور انس Lawrence (2017) دراسة هدفت إلى اقتراح نموذج لتعلم اللغة الأجنبية للأطفال في المرحلة الابتدائية وما قبل المرحلة الابتدائية في فنلندا، مع التركيز على المرح و اللعب والاحتياجات العاطفية، ويعتمد النموذج على مجموعة واسعة من الأدبيات حول تنمية الأطفال والتعليم وتعلم اللغات الأجنبية على وجه التحديد. وقد تم استقصاء معلمي اللغة الأجنبية لاكتشاف ممارساتهم الحالية في دعم تعلم اللغة الأجنبية مع متعلميهم، ثم تحليل هذه البيانات ومقارنتها بالنموذج المقترح. وتوصلت الدراسة إلى أن العديد من المعلمين يتبعون بالفعل العديد من مبادئ النموذج المقترح في ممارساتهم 
أ.م.د/ وفاء بنت عايض سعد الحارثي

اليومية، كاستخدام الأنشطة الترفيهية، والوعي بمشاعر المتعلمين، وتعلم اللغة بمساعدة

الكمبيوتر.

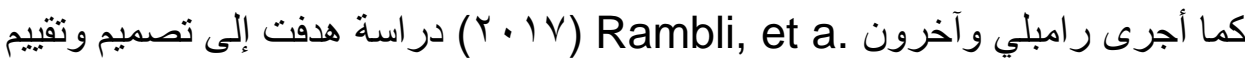
كتاب لتعليم الأبجدية للأطفال بإدخال المتعة والتعليم التفاعلي من خلال استخدام كتاب (آر) المصور، وتوظيف اللعب والدراما، والأغاني، واستخدام تكنولوجيا المعلومات. وتكونت عينة الدراسة من (10) طفل تراوحت أعمار هم من (0-7) سنوات في إحدى مدارس ماليزيا، وقد جمعت الدراسة بين المنهج الكمي والنوعي؛ حيث تمت ملاحظة الأطفال أثناء عملية التعلم، ورصد تفاعلهم بواسطة تسجيل فيديو، كما تم استخدام المقابلة القصيرة مع المعلم، كما نم استخدام استبيان بسيط لرصد مشاعر التلاميذ باستخدام السؤال و الصور المعبرة عن مدى رضاه وشعوره بالمتعة والفرح، وتوصلت الدراسة إلى زيادة واضحة لدى التلاميذ في القدرة على حفظ وفهم المفاهيم والمفردات التي يتضمنها الكتاب، حيث أفاد المعلمون أن اللعب هو الوسيلة المناسبة لتعليم الأطفال

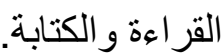

كما هدفت دراسة خير الله وروحمي Khorual \& Rohmy (7 ( • ب) إلى تقييم أنشطة متكاملة قائمة على المهام وتعليم اللغة الإنجليزية لتلاميذ المرحلة الابتدائية بمساعدة الحاسوب بإندونيسيا، وتكونت الخطوات الإجرائية لتنفيذ المواقف التعليمية من خلال عرض متناقضات تعليمية تتطلب دراستها عدة مراحل (المراقبة، الاستجواب، الاستكثاف، التواصل)، و أنشارت نتائج الدراسة إلى فاعلية البرنامج في تنمية التفكير الابتكاري المرتبط بدراسة اللغة لدى تلاميذ المرحلة الابتدائية بشكل أكثر ابتكار ا ومتعة.

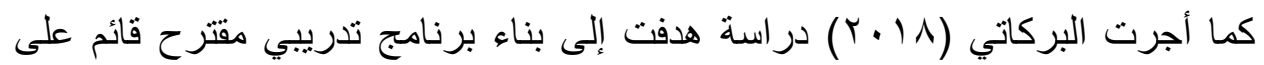
استر اتيجيات التعلم الممتع لمعلمات الرياضيات بالمرحلة الابتدائية بمدينة مكة المكرمة. وقامت الباحثة بتصميم استبانة لتحديد استخدام معلمات الرياضيات لاستر اتيجيات التعلم الممتع ومعرفة الاحتياجات، ومن ثم تحديد معوقات استخدامها من قبلهن، وزعت على 
واقع استخدام معلمات اللغة العببية للمرحلة الابتدائية لاستراتيجيات التعلم الممتع بمدينة الرياض

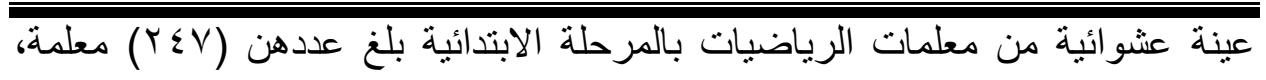
وخلصت الدراسة إلى تحديد قائمة بأساليب و استر اتيجيات التعلم الممتع والمستخدمة من قبل معلمات الرياضيات، حيث أظهرت تدني في نسب الاستخدام، كذلك تحديد مجموعة من الاحتباجات التدريبية اللازمة لمعلمات الرياضيات بالمرحلة الابتدائية لكل من أساليب و استر اتيجيات التعلم المتع، ووسائله و أنشطته و أساليب تقويمه، ومن ثم وضع برنامج تدريبي مقتر ح قائم على استر اتيجيات التعلم الممتع لمعلمات الرياضيات بالمرحلة. تنو عت أهداف الدراسات السابقة فهدفت دراسة إلى تعرف درجة استخدام معلمي اللغة للمرحلة الابتدائية لاستراتيجيات التعلم الممتع وهذا ما يتفق مع الدراسة الحالية، بينما هدفت دراسة رامبلي وآخرون، ودراسة خير الله وروحمي إلى تعرف فاعلية برامج و استر اتيجيات التعلم المتع في تنمية المهار ات اللغوية لدى المتعلمين، كما هدفت در اسة البركاتي إلى بناء برنامج تدريبي مقترح قائم على استر اتيجيات التعلم الممتع بعد تعرف درجة استخدام معلمات الرياضيات للمرحلة الابتدائية لاستر اتيجيات التعلم المتع، وتتفق الدراسة الحالية مع هذه الدراسة في استهدافها معلمات المرحلة الابتدائية ودراسة أثر المتغيرات الديموغر افية على مدى استخدام المعلمات لاستراتيجيات التعلم المتع. وتختلف الدراسة الحالية عن الدراسات السابقة في أنها أول دراسة ـ حسب علم الباحثة. أجريت في مجال تدريس اللغة العربية. وقد تمت الاستفادة من الدراسات السابقة في إثراء الجانب النظري للار اسة الحالية، والإطار العام للار اسة، وبناء أداتها، والتحليل الإحصائي. منهج الدراسة وإجراءاتها:

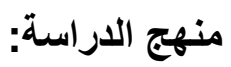
اعتمدت الباحثة على المنهج الوصفي نظر الملاءمته لطبيعة المشكلة. 
يمثل مجتمع الدراسة جميع معلمات اللغة العربية بالمرحلة الابتدائية في المدارس

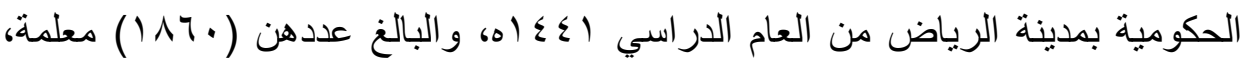

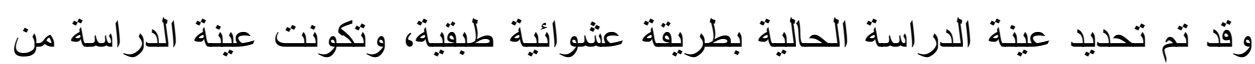

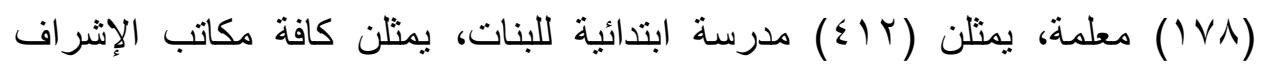
التربوي البالغ عددها تسعة مكاتب بمدينة الرياض.

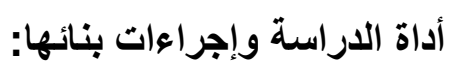
بناء على طبيعة البيانات المر اد جمعها، وعلى المنهج المتبع في الدراسة، استخذمت الباحثة الاستبانة في هذه الدراسة، وقامت بإعداد أداة الدراسة على النحو الآتي:

أـ تحديد الهلف من الاستبانة: في ضوء أهداف الدراسة ومتغيراتها، نم تحديد الهدف من الاستبانة، وهو نعرف واقع استخدام معلمات اللغة العربية بالمرحلة الابندائية

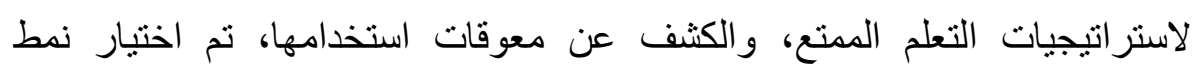
الاستبانة المغلق؛ نظرا لأنه أكثر كفاء في الحصول على المعلومات المطلوبة الكاتية للار اسة، الإضافة إلى سهولة تجميع وتبويب وتحليل المعلومات المجمعة من خلاله.

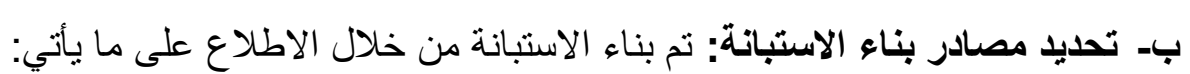

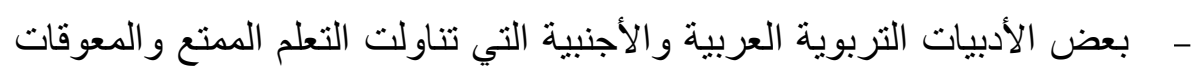
التي تواجه معلمات المرحلة الابتدائية لاستخدامه.

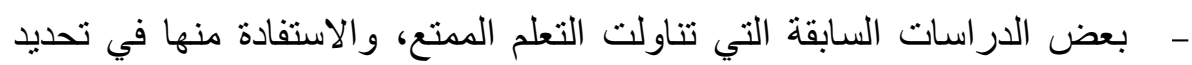

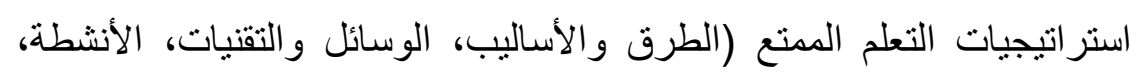

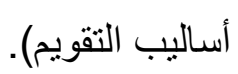
- - بعض الاستبيانات الخاصة بالتعلم الممتع ومعوقات استخدامه التي تواجه معلمات المرحلة الابتدائية.

العدد الخامس والاربعون (الجزء الاول) ا Y.r.

(165)
مجلة كلية التربية- جامعة عين شمس 
واقع استخدام معلمات اللغة العربية للمرحلة الابتدائية لاستراتيجيات التعلم الممتع بمدينة الرياض

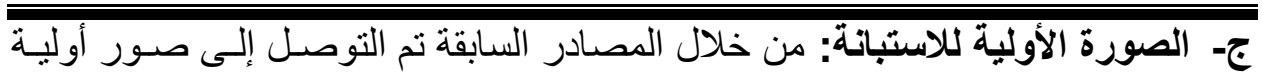
للاستبانة، حيث اشتملت على جز أين:

- ـ الجزء الأول: يشتمل على المعلومات الأوليـة للمعلمـة، وهـي: العمـر، و المؤهل

$$
\text { العلمي، و عدد سنوات الخبرة، و الدور ات التدريبية. }
$$

- الجزء الثاني: يشتمل على مفردات الاستبانة، ويتكون من محورين: - - المحور الأول: واقع استخدام معلمات اللغة العربية لاستراتيجيات التعلم المتع،

$$
\text { ويشنمل على (ON) مفردة. }
$$

- - المحور الثاني: معوقات استخدام معلمات اللغة العربية لاستراتيجيات التعلم

$$
\text { المثتع، ويشنمل على (1/) عبارة. }
$$

د- صدق أداة الدراسة وثباتها:

\section{قامت الباحثة بالتأكد من صدق أداة الدر اسة من خلال ما يأتي:}

- الصدق الظاهري: للتأكد من صدق الاستبانة؛ تم عرضها في صـورتها المبدئية على عدد من الخبراء و المتخصصين في المناهج وطرق تدريس اللغـة العربيـة، وقد أعدت الباحثة استمارة خاصة للتعرف على آراء المحكمين حول (ملاءمـة الفقر ات للمحاور، وضوح صـياغتها، و وناسبتها لتلميذات المرحلـة الابتدائيـة)،

$$
\text { وعدلت وفق آر ائهم. }
$$

- صدق الاتساق الداخلي: للتحقق من صدق الاتساق الداخلي للاستبانة، تم حسـاب (معامل ارتباط بيرسون)، واتضح أن قيم معامل ارتباط كل عبارة من العبار ات التئل

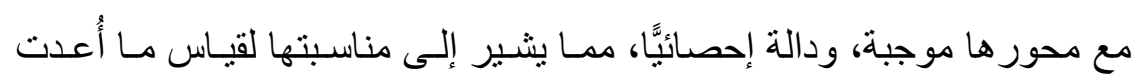
لقياسه. 
أ.م.د/ وفاء بنت عايض سعد الحارثي

ه- ثبات أداة الاراسة: تم التأكد من ثبات الأداة من خلال استخدام (معادلة ألفا

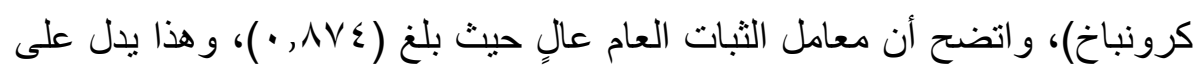
أن الاستبانة تتمتع بدرجة ثبات مرتفعة يمكن الاعتماد عليها في التطبيق الميداني للدر اسة. و- تحديــ أسـلوب تصـحيح الاسـتبانة: تـم اسـتخدام المقيـاس الثلاثتي للحصـول على

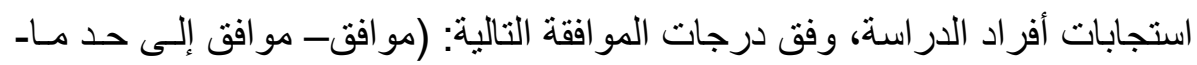
غير موافق) و(أستخدم - أستخدم إلى حد ما - لا أستخدم). جدول ( () المحك المستخدم في الدر اسة (حدود متوسطات الاستجابات)

\begin{tabular}{|c|c|c|c|}
\hline \multicolumn{2}{|c|}{ حدود الفئة } & \multirow[t]{2}{*}{ الفئة } & \multirow[t]{2}{*}{ م } \\
\hline إلى & من & & \\
\hline$\cdot, \pi$ & $\cdot, \ldots$ & ضعيف & 1 \\
\hline$\cdot, 77$ & $\cdot, \Gamma \varepsilon$ & متوسط & $r$ \\
\hline $1, \ldots$ & $\cdot, T V$ & عالى & $r$ \\
\hline
\end{tabular}
مفردات الدراسة، بعد معالجتها إحصائياً. ز- الاستبيان في صورته النهائية: بعد التأكد مـن صدق الاستبانة، وثباتـه، أصبح في صورته النهائية يتكون من محورين رئيسيين، اندرج تحتها (0ب) فقرة.

إجراعات تطبيق أداة الدراسة: بعد الحصـول على إحصـائيات عن عدد معلمـات اللغـة العربيـة بالمرحلـة الابتدائيـة في المـدارس الحكوميـة بمدينـة الريـاض، تـم اختيـار عينـة

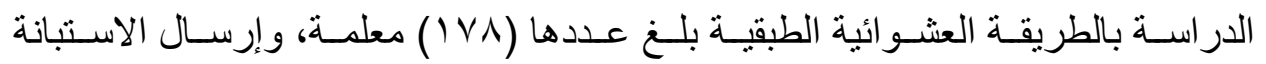
الإلكترونية على الواتس اب، ولكن س ا ـ ؟ فقط استجاب مدا الدر اسة، ثم جرى بعد ذلك جمعها، وتفريغها، وتحليلها إحصائيا، واستخلاص النتائج منها. 
واقع استخدام معلمات اللغة العببية للمرحلة الابتدائية لاستراتيجيات التعلم الممتع بمدينة الرياض

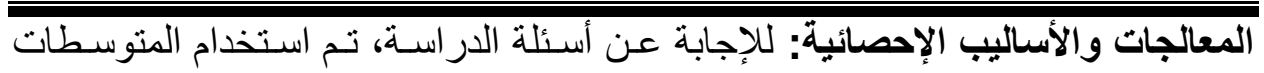
الحسـابية، و الانحر افـات المعياريـة لكـل فقر مـن فقـرات الاسـنبانة، اختبـار ت لعينتـين مستقلتين، واختبار تحليل التباين الأحادي One- way ANOVA. نتائج الدراسة ومناقشتها: إجابة السؤال الأول والذي ينص على: "ما درجة استخدام معلمات اللغة العربية بالمرحلة الابتدائية لاستراتيجيات التعلم المتع (الطرق والأساليب، الوسائل والتقتيات، الأنشطة، أساليب التقويم")؟ بالهرجل (أ) طرق وأساليب التعلم الممتع:

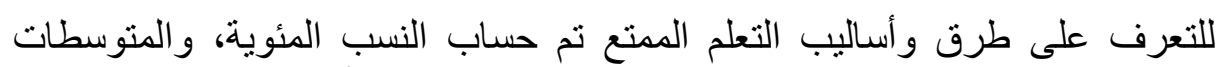

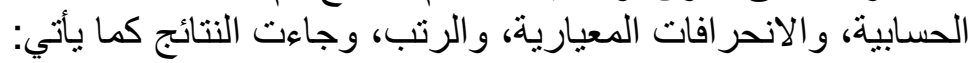

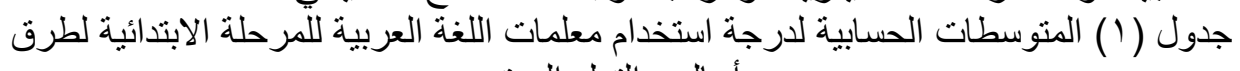

\begin{tabular}{|c|c|c|c|c|c|}
\hline$\overline{3}$ & الانحرا & النسبي & الحستبي & العبارات & p \\
\hline 1 &., 190 & $\% \wedge 0$ & $\cdot .10$ & التعلم التعاوني & $\Lambda$ \\
\hline r & $\cdot, r \cdot r$ & $\% \wedge$ & $\cdot \wedge$. & القصة التعليمية & v \\
\hline$r$ & $\cdot, \Pi V$ & $\% \wedge$ & $\cdot . \wedge$. & لعب الأدو ار & 7 \\
\hline$\varepsilon$ & ד דזז, & $\% \wedge$ & $\cdot \wedge$. & التعلم باللعب & 0 \\
\hline 0 & $\cdot, \pi 70$ & $\% \vee 0$ & $\therefore$ Vo & خر ائط التفكير & 1. \\
\hline 7 & $\cdot$ r rVo & $\% 70$ &. .70 & التعلم بالممارسة & 9 \\
\hline $\mathrm{v}$ & $\cdot, \varepsilon Y \uparrow$ & $\% \vee \neg$ &. .17 & الطر ائف العلمية & 1 \\
\hline$\wedge$ & $\cdot, \leqslant 09$ & $\%$ & $\therefore V$. & التعلم بالأناشيد و الأشعار & $r$ \\
\hline 9 & $\cdot, \sum 71$ & $\%$ & $\therefore v$ & الرسوم الكرنونية & 11 \\
\hline 1. & $\cdot, \leqslant \Lambda$ & $\%$ & .7 & التعلم بالأحاجي و الألغاز & $\varepsilon$ \\
\hline 11 & $\cdot, \varepsilon r q$ & $\% 07$ & .07 & التدريس التبادلي & ir \\
\hline ir & $\cdot, \leqslant \wedge$. & $\% \pi r$ & $\cdot \pi \mu$ & الذكاءات المتعددة & $1 \varepsilon$ \\
\hline 14 & $\cdot, \varepsilon 9 \leqslant$ & $\% r$ & 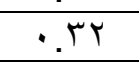 & |المسرحية التعليمية & $r$ \\
\hline $1 \leq$ & $\cdot, \leqslant 10$ & $\% 10$ &. .10 & الرحلات العلمية عبر الويب & 14 \\
\hline \multicolumn{2}{|c|}{$\cdot, Y \cdot \Lambda$} & $\%$ & $.7 \pi$ & المتوسط العام & \\
\hline
\end{tabular}

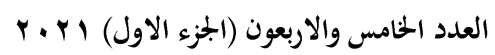

(168)

مجلة كلية التربية- جامعة عين شمس 
يتضح من الجدول السابق أن المتوسط العام لدرجة استخدام معلمات اللغة العربية للمرحلة الابتدائية لطرق وأساليب التعلم الممتع بلغ با7. • وهو ما يشير إلى أن موافقة أفر اد الدر اسة على استخدام طرق وأساليب التعلم المتع جاءت بدرجة متوسطة. كما يتضح من الجدول السابق أن هناك من استراتيجيات التعلم الممتع ما زادت نسبة استخدامها عن (77\%) و هي (التعلم التعاوني، القصة التعليمية، لعب الأدوار، التعلم باللعب، خرائط التفكير) وتعزو الباحثة ذلك إلى تلقي المعلمات دورات مكثفة عنها،

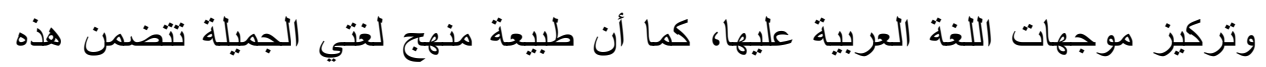
الاستر اتيجيات، وتتفق هذه النتيجة مع ما توصلت إليه دراسة رامبلي وآخرون التي أفاد

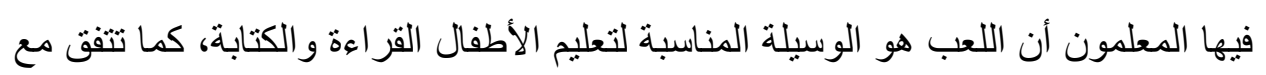
در اسة لور انس ودر اسة البركاتي التي توصلت إلى أن المعلمين يستخدمون بالفعل اللعب

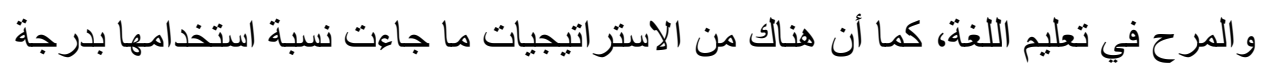

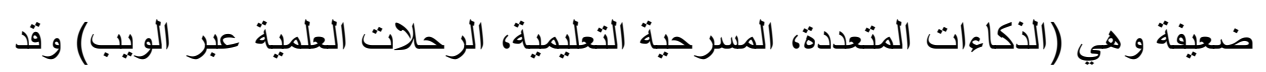

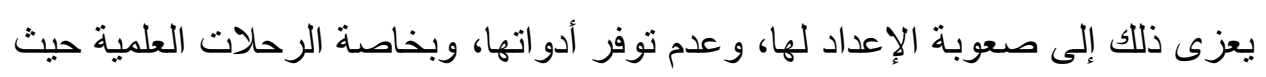
تعتمد أساسًا على التقنية، كذلك عدم تلقي المعلمات دورات تدريبية كافية عنها، وهذه

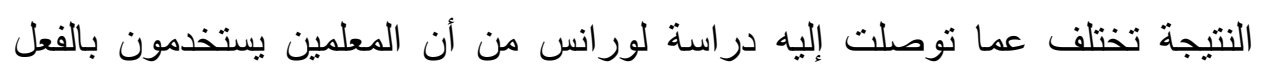
استر اتيجية تعلم اللغة بمساعدة الكمبيوتر. (ب) وسائل وتقنيات التعلم الممتع: للتعرف على وسائل وتقنيات التعلم الممتع تم حساب النسب المئوية، والمتوسطات الحسابية، و الانحر افات المعيارية، والرتب، وجاءت ولنيات النتائج كما يأتي: 
واقع استخدام معلمات اللغة العربية للمرحلة الابتدائية لاستراتيجيات التعلم الممتع بمدينة الرياض

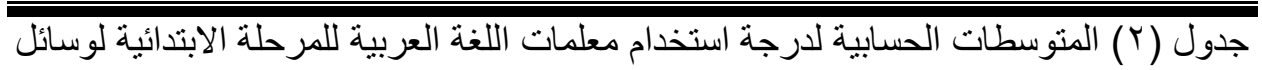

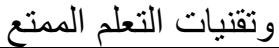

\begin{tabular}{|c|c|c|c|c|c|}
\hline (⿹) & المعياري & النسبي & الحستابي & العبارات & p \\
\hline 1 & $\cdot, r V$. & $\% 9 r$ & $\cdot .9 r$ & البطاقات و الصور & 7 \\
\hline$r$ & $\cdot, Y 90$ & $\% \wedge \wedge$ & $\cdot . \wedge \wedge$ & مسجل الصوت & $\wedge$ \\
\hline$r$ & $\cdot, r 90$ & $\% \wedge V$ & $\cdot . \wedge \mathrm{V}$ & الأفلام القصبرة من اليوتيوب & 1. \\
\hline$\varepsilon$ & $\cdot, \leqslant 10$ & $\% \vee 0$ & $\because \mathrm{VO}^{\circ}$ & الألعاب التعليمية & 0 \\
\hline 0 & $\cdot, \varepsilon Y q$ & $\% \vee r$ & $\therefore V Y$ & تطبيقات على الَآيباد و الهو اتف النقالة & 1 \\
\hline 7 & $\cdot, \leqslant 01$ & $\% \pi r$ &. $.7 T$ & بطاقات الرسم & V \\
\hline V &., $0 \ldots$ & $\% \Sigma \Gamma$ & $\cdot . \Sigma \Gamma$ & دمى لتمثيل الأدوار و القصص & $r$ \\
\hline$\wedge$ & $\cdot, 0.1$ & $\%$ \% & $\cdot . M Y$ & السبورة الذكية & $\varepsilon$ \\
\hline 9 & $\cdot, \sum 91$ & $\%$ \%. & $\cdot r$. & القصص الرقمية & $r$ \\
\hline 1. & $\cdot, \leqslant \leqslant 0$ & $\% Y V$ & $\cdot r V$ & الرحلات التعليمية & 9 \\
\hline \multicolumn{2}{|c|}{., 519} & $\% 71$ & $\cdot, 7)$ & المتو سط العام & \\
\hline
\end{tabular}

يتضح من الجدول السابق أن المتوسط العام لدرجة استخدام معلمات اللغة العربية للمرحلة الابتدائية لوسائل وتقنيات التعلم الممتع بلغ ( (7, · · ) وهو ما يثير إلى أن موافقة أفر اد الدر اسة على استخدام وسائل وتقنيات التعلم الممتع جاءت بدرجة متوسطة. يتضح كذلك من الجدول السابق أن هناك من وسائل وتقنيات التعلم الممتع ما زادت نسبة استخدامها عن (77\%) وهي (البطاقات والصور، مسجل الصوت، الأفلام القصيرة من اليوتيوب، الألعاب التعليمية، تطبيقات على الآيباد والهواتف النقالة) وتعزو الباحثة

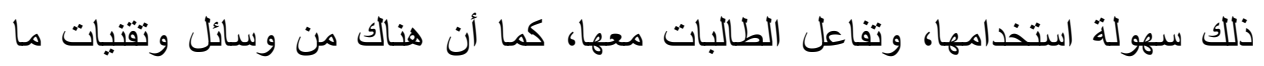
جاءت نسبة استخدامها بدرجة ضعيفة وهي (السبورة الذكية، القصص الرقمية، الرحلات التعليمية) وقد يعزى ذللك إلى عدم توفر التقنيات اللازمة لها، أو عدم معرفة المعلمات بطريقة تنفيذها، أما بالنسبة للرحلات التعليمية فقد يعزى تدني نسبة استخدامها لكثرة أعداد الطالبات، وصعوبة الإعداد لها، وتتفق هذه النتيجة مع ما توصلت إليه دراسة البركاتي التي أنثارت إلى أن (السبورة الذكية، القصص الرقمية، الرحلات التعليمية) كانت من الوسائل التي حصلت على نسبة مندنية في استخدامها من قبل المعلمات. 
أ.م.د// وفاء بنت عايض سعد الحارثي

(ج) (أنشطة التعلم الممتع:

للتعرف على أنشطة التعلم الممتع تم حساب النسب المئوية، والمتوسطات الحسابية، و الانحر افات المعيارية، والرتب، وجاءت النتائج كما يأتي:

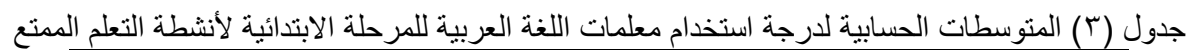

\begin{tabular}{|c|c|c|c|c|c|}
\hline$\overline{3}$ & الالمعراف & النسبي\% الوزن & الحستوسطي & العبارات & b \\
\hline 1 & $\cdot, Y \wedge V$ & $\% 91$ & $\cdot 91$ & أنشطة النقاش و الحوار & 7 \\
\hline$r$ & $\cdot, r \leqslant \Lambda$ & $\%$ \% & $\cdot, \lambda r$ & مسابقات بين الفرق & $\mathrm{V}$ \\
\hline$r$ & $\cdot, \leqslant 9$. & $\% 71$ & $\cdot, 71$ & لعبة الكلمات المتقاطعة & 0 \\
\hline$\varepsilon$ & $\cdot, \leqslant 90$ & $\% .01$ & $\cdot, 01$ & تصميم الرسوم و الصور & $r$ \\
\hline 0 &., 0.1 & $\% \varepsilon r$ &.$\Sigma Y$ & الألغاز الصورية & $\varepsilon$ \\
\hline 7 & $\cdot, \leqslant 90$ & $\%$ \% &.$\Gamma \Lambda$ & إنتاج التقارير & $\Lambda$ \\
\hline$V$ & $\cdot, \varepsilon 9 \wedge$ & \% & 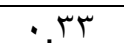 & لعبة كلمة السر & $r$ \\
\hline$\wedge$ & $\cdot, \leqslant 9 \leqslant$ & \% & . & لعبة المتاهة & 1 \\
\hline \multicolumn{2}{|c|}{$\cdot, Y \wedge \wedge$} & $\% 00$ &., 00 & \multicolumn{2}{|l|}{ المتوسط العام } \\
\hline
\end{tabular}

يتضح من الجدول السابق أن المتوسط العام للرجة استخدام معلمات اللغة العربية

للمرحلة الابتدائية لأنشطة التعلم المتع بلغ ه9, . ، وهو ما يثير إلى أن موافقة أفراد

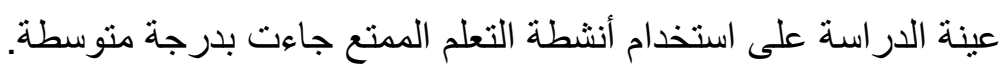
يتضح كذلك من الجدول السابق أن هناك من أنشطة التعلم المتع ما زادت نسبة استخدامها عن (77\%) وهي (أنشطة النقاش والحوار، ومسابقات بين الفرق) وتعزو الباحثة ذلك سهولة استخدامها، وتفاعل الطالبات معها، وتتفق هذه الدراسة مع دراسة

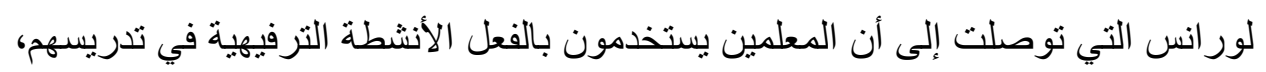
و على الرغم من أهمية الألعاب في التعلم وخاصة في التعلم الممتع إلا أنه يلاحظ أن لن لئل (لعبة كلمة السر، ولعبة المتاهة) جاءت نسبة استخدامها بدرجة ضعيفة وقد يعزى ذلك الك لعدم توفر الوقت الكافي لايهن لبناء الأنشطة، حيث يكون التركيز الأساسي على الأنشطة

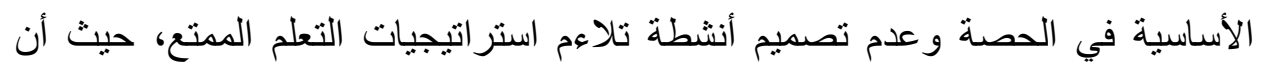
المعلمة مطالبة بإنهاء المقرر في فترة زمنية محددة، وقد ذكرت المعلمات أن من الصعوبات التي تواجهرن كثرة الأنشطة المخصصة للاروس، وتتقق هذه النتيجة مع ما في

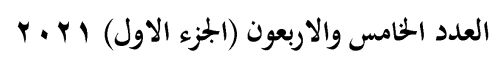

مجلة كلية التربية- جامعة عين شمس 
واقع استخدام معلمات اللغة العربية للمرحلة الابتدائية لاستراتيجيات التعلم المتع بمدينة الرياض توصلت إليه دراسة البركاتي التي أشنارت إلى أن لعبة المتاهة ولعبة كلمة السر ولعبة لإنة

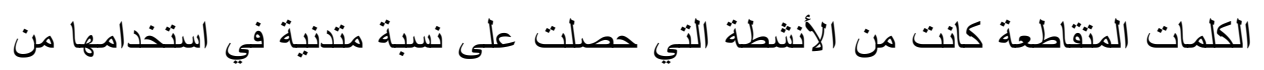
قبل المعلمات.

$$
\text { (د) أساليب تقويم التعلم المثتع: }
$$

للتعرف على أساليب تقويم التعلم الممتع تم حساب النسب المئوية، والمتوسطات الحسابية، و الانحر افات المعيارية، والرتب، وجاءت النتائج كما يأني: جدول ( ) المتوسطات الحسابية لدرجة استخدام معلمات اللغة العربية للمرحلة الابتدائية لأساليب تقويم التعلم الممتع

\begin{tabular}{|c|c|c|c|c|c|}
\hline$\overline{\overline{7}}$ & الالنعراف & النسبي & الحسابي & العبار ات & 5 \\
\hline 1 & $\cdot, r \cdot \Lambda$ & $\% 97$ & $\cdot, 97$ & الورقة و القلم & 7 \\
\hline r & $\cdot, r 90$ & $\%$ & $\cdot, 9$. & ملفات الإنجاز & 1 \\
\hline$r$ & $\cdot, T \cdot Y$ & $\% 9$. & $\cdot, 9$ & 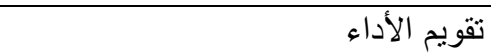 & r \\
\hline$\varepsilon$ & $\cdot, r 90$ & $\% 9$ & $\cdot, 9$. & التقويم الذاتي & $r$ \\
\hline 0 & 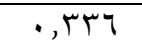 & $\% \wedge \mathrm{V}$ & $\cdot, \mathrm{AV}$ & خر ائط المفاهيم & 0 \\
\hline 7 & $\cdot, r \wedge 0$ & $\%$ \% & $\cdot, A r$ & تقويم الأقران & $\mathrm{v}$ \\
\hline V & $\cdot, r 9 \leq$ & $\% \wedge 1$ & $\cdot, \lambda)$ & المشرو عات & $\varepsilon$ \\
\hline$\Lambda$ & $\cdot, \varepsilon \Psi_{4}$ & $\%$ Vo & $\cdot$, Vo & الوجه الملائم (سعيد، لا شعور، حزين) & $\Lambda$ \\
\hline \multicolumn{2}{|c|}{$\cdot, r \cdot 1$} & $\% \wedge \uparrow$ & $\cdot, \wedge 7$ & \multicolumn{2}{|l|}{ المتوسط العام } \\
\hline
\end{tabular}

يتضح من الجدول السابق أن المتوسط العام لدرجة استخدام معلمات اللغة العربية للمرحلة الابتدائية لأساليب تقويم التعلم الممتع بلغ بمر, · وهو ما يثير إلى أن موافقة

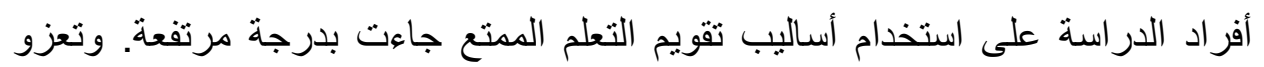
الباحثة ذلك إلى تلقي المعلمات دورات مكثفة عنها. إجابة السؤال الثاني والذي ينص على: "ما معوقات استخدام معلمات اللغة العربية بالمرحلة الابتدائية لاستراتيجيات التعلم المتع" 
للتعرف على معوقات استخدام استراتيجيات التعلم المثتع نم حساب النسب المئوية، و المتوسطات الحسابية، والانحر افات المعيارية، والرتب، وجاءت النتائج كما يأتي: جدول (0) استجابات أفر اد الدراسة حول معوقات استخدام استر اتيجيات التعلم الممتع حسب متوسطات المو افقة

\begin{tabular}{|c|c|c|c|c|c|}
\hline : & الانحر اف المعياري & 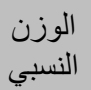 & الحسابي & 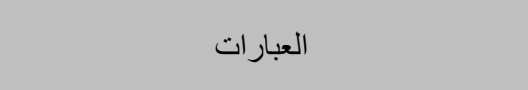 & s \\
\hline 1 & $\cdot, r \cdot r$ & $\%$ & $\cdot, 9$. & كثرة عدد التلميذات في الصف الدر اسي & Ir \\
\hline r & 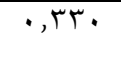 & $\% \wedge \wedge$ & $\cdot, \wedge \wedge$ & التعلم الممتع توفر ميز انية لتوفير وسائل و أدوات & 1 \\
\hline$r$ & • & $\% \wedge \wedge$ & $\cdot, \wedge \wedge$ & ضيق مساحة الصف الدر اسي & 14 \\
\hline$\varepsilon$ & $\cdot, r \leq r$ & $\%$ «V & $\cdot, \wedge \mathrm{V}$ & قلة الحو افز المادية للمعلمات المتدربات & $\varepsilon$ \\
\hline 0 & $\cdot, \Sigma \cdot V$ & $\% \vee 9$ & $\cdot, \vee \vee 9$ & (لغتي) & 1 . \\
\hline 7 & $\cdot, \leqslant 10$ & $\% \vee \wedge$ & $\cdot, \vee \wedge$ & التعلم الممتع توفر أدلة إرشادية لتطبيق استر اتيجيات & 11 \\
\hline $\mathrm{V}$ & $\cdot, \leqslant 19$ & $\% \vee \wedge$ & $\cdot, \vee \wedge$ & 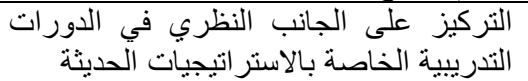 & 10 \\
\hline$\wedge$ & $\cdot, \leqslant 0 \%$ & $\% \vee 1$ & $\cdot,(\mathrm{V}$ & عدم وجود نظام يحفز المعلمة على استخدام & IV \\
\hline 9 & $\cdot, \leqslant 77$ & $\% 79$ & $\cdot, 79$ & ضعف البنية التحتية للمدرسة & $r$ \\
\hline $1 \cdot$ & $\cdot, \leqslant 77$ & $\% 79$ & $\cdot, 79$ & نقص خبرة المعلمات باستر اتيجيات التعلم & 0 \\
\hline 11 & $\cdot, \preceq \wedge \vee$ & $\%$ \% & $\cdot, 7 Y$ & 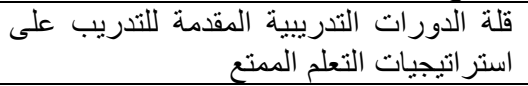 & $r$ \\
\hline IT & $\cdot, 0.1$ & $\% 01$ &., 01 & قلة الوقت المخصص للحصة الدر اسبة & 9 \\
\hline 14 & $\cdot, 0.1$ & $\% 01$ & $\cdot, 01$ & الإشر افية الإشر كالدروس التربوي في تنفيذ الأساليب & $1 \leqslant$ \\
\hline $1 \leqslant$ & $\cdot, 0.1$ & $\% \leqslant \wedge$ & $\cdot, \leqslant \Lambda$ & التعلم الممتع تقبل المعلمات لتطبيق استراتيجيات & 7 \\
\hline 10 & $\cdot, \varepsilon 9\}$ & $\% \varepsilon$ & $\cdot, \varepsilon \cdot$ & عدم قدرة المعلمة لضبط الصف الثناء تطبيق المثلى المباء & V \\
\hline 17 & $\cdot, \varepsilon 9 r$ & $\% \varepsilon$. & $\cdot, \varepsilon$. & التقليدي في السيطرة المعلمة على التخلي العملية التعليمبة دورها & $\wedge$ \\
\hline IV & $\cdot, \leqslant 9 r$ & $\% \varepsilon$. & •, $\varepsilon$. & إلتدريبية المعلمات عن عضور الدورات & 17 \\
\hline \multicolumn{2}{|c|}{$\cdot, Y)$. } & $\% 77$ & $\cdot, 77$ & المتوسط العام & \\
\hline
\end{tabular}

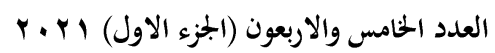

(173)

مجلة كلية التربية- جامعة عين شمس 
واقع استخدام معلمات اللغة العببية للمرحلة الابتائية لاستراتيجيات التعلم الممتع بمدينة الرياض

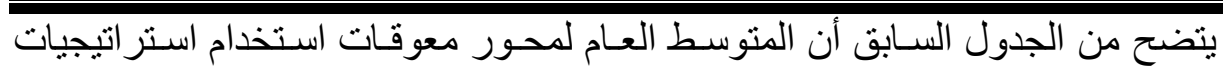
التعلم الممتع بلغ 77 , • و هو ما يشير إلى أن مو افقة أفراد الدراسة على معوقات استخدام استر اتيجيات التعلم الممتع جاءت بدرجة مرتفعة.

كما يتضح من المتوسطات الحسابية لفقرات هذا المحور أنها تراوحت مـا بين ( 9 ، . . إلى • ع , ·)، فقد حصلت عبارة (كثرة عدد التلميذات في الصف الدراسي) على أعلى متوسط ومقداره ( • 9 • ·)، يليها عبارة (عدم توفر ميز انيـة لتوفير وسـائل وأدوات التعلم الممتع) و عبارة (ضيق مساحة الصف الدراسي بحيث لا يسمح بإعادة ترتيبه ليتلاءم مـع

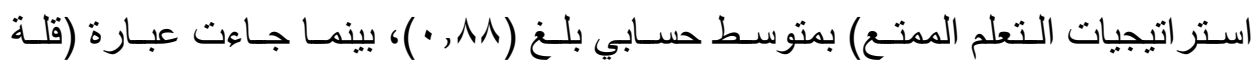
الحو افز المادية للمعلمات المتدربات) بمتوسط حسابي بلغ (V9 , · ) ويلاحظ أن المعوقـات السابقة تتعلق بالجانب المادي حيث يستلزم تقليل أعداد الطالبات في الصف الدراسـي إلى لى زيادة المباني المدرسية، كما أن تقديم الحو افز المادية للمعلمات المتدربات وتوفير وسـائل و أدوات التعلم الممتع - خاصة التقنية منها- تحتاج إلى ميز انية خاصة، كما جاءت عبارة (عدم تقبل المعلمات لتطبيق استر اتيجيات التعلم المتع) من بين العبـارات الحاصـلة على إسى

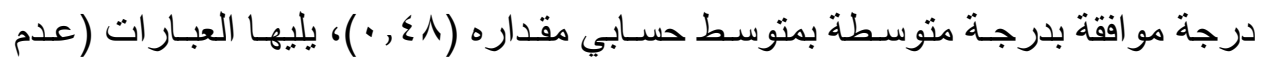
قدرة المعلمة لضبط الصف أثناء تطبيق استر اتيجيات التعلم المثتع)، و(عدم قدرة المعلمـة على التخلي عن دور ها التقليدي في السيطرة على العطليـة التعليميـة)، (إحجـام المعلمـات عن حضور الدورات التدريية) حيث حصلت على أدنى منوسط حسابي مقداره ( • ؛ . •) ويلاحظ أنها جميعا تتعلق بالمعلمة، وقد يعود السبب في ذلك إلى إدر اكهن لأهميـة تطبيق استر اتيجيات التعلم المتع و أهمية حضور الدورات التدريبية المتعلقة بها.

ع. إجابة السؤال الثالث والأي ينص على: هل توجد فروق ذات دلالة إحصائية عند مستوى (ه., •) في درجة استخدام معلمات اللغة العربية بالمرحلة الابتدائية 
أ.م.د/ وفاء بنت عايض سعد الحارثي

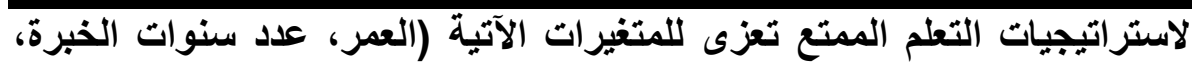

والمؤهل العلمي، وعدد الدورات التدريبية)؟

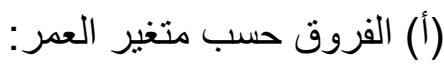

لمعرفة ما إذا كانت هنالك فروق ذات دلالة إحصائية في إجابات أفراد عينة الدر اسة

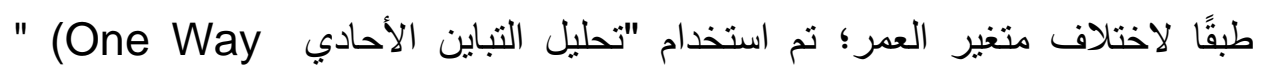
ANOVA) جدول (7) نتائج "تحليل التباين الأحادي" (One Way ANOVA) للفروق في إجابات أفراد عينة الدراسة طبقًا لاختلاف العمر

\begin{tabular}{|c|c|c|c|c|c|c|}
\hline الإحصائية الإة & قيمة ف & متوسط & | & مربعات & مصدر التباين & المحور \\
\hline \multirow{3}{*}{$\cdot, 119$} & \multirow{3}{*}{$r, 101$} &., .94 & $r$ & $\cdot, 110$ & بين المجموعات & \multirow{3}{*}{ طرق وأساليب التعلم الممتع } \\
\hline & & $\cdot, \cdot \leq \pi$ & 180 & $v, 0.9$ & داخل المجمو عات & \\
\hline & & & $I V V$ & $v, 79 \leq$ & المجموع & \\
\hline \multirow{3}{*}{$\cdot, \ldots 1$} & \multirow{3}{*}{$V, 001$} & q & $r$ & $\cdot, 7 \vee 9$ & بين المجموعات & \multirow{3}{*}{ وسائل وتقنيات استر اتيجيات } \\
\hline & & $\cdot, \cdot \leq 0$ & 180 & $\mathrm{~V}, \wedge>0$ & داخل المجمو عات & \\
\hline & & & $I V V$ & $\wedge, 0 \leq \leqslant$ & المجموع & \\
\hline \multirow{3}{*}{$\cdot, \cdot 1 \leq$} & \multirow{3}{*}{$\varepsilon, \varepsilon \cdot \varepsilon$} & $\cdot$, TOY & $r$ & $\cdot, V \cdot O$ & بين المجموعات & \multirow{3}{*}{ أنشطة تنفيذ استر اتيجيات التعلم } \\
\hline & & $\cdot, \cdot \wedge$. & 1Vo & $1 \varepsilon$ & داخل المجمو عات & \\
\hline & & & $I V V$ & $1 \varepsilon, V \cdot 0$ & المجموع & \\
\hline \multirow{3}{*}{$\cdot, \cdot Y r$} & \multirow{3}{*}{$r, \wedge \wedge \mu$} &., $10 Y$ & $r$ & $\cdot r \cdot r$ & بين المجمو عات & \multirow{3}{*}{ أساليب تقويم استر اتيجيات التعلم } \\
\hline & &., $.4 q$ & 180 & $7, \wedge M_{1}$ & داخل المجمو عات & \\
\hline & & & $I V V$ & $V, I T \varepsilon$ & المجموع & \\
\hline \multirow{3}{*}{., 101} & \multirow{3}{*}{$1,91}$. & $\cdot, \cdot \wedge \varepsilon$ & $r$ & $\cdot, 17 \mathrm{~V}$ & بين المجموعات & \multirow{3}{*}{ معوقات استخدام استر اتيجيات } \\
\hline & & $\cdot, \cdot \leq \varepsilon$ & 180 & $v, 701$ & داخل المجمو عات & \\
\hline & & & $I V V$ & $V, \wedge Y 0$ & المجمو ع & \\
\hline
\end{tabular}

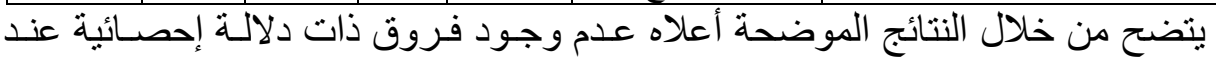
مسـتوى (0. . · ) فأقل في إجابـات أفراد عينـة الدراسـة حـول (طـرق وأسـاليب التعلم الممتع، و أنشطة تنفيذ استر اتيجيات التعلم الممتع، ومعوقات استخدام استر اتيجيات التعلم الممتع) باختلاف متغير العمر. 


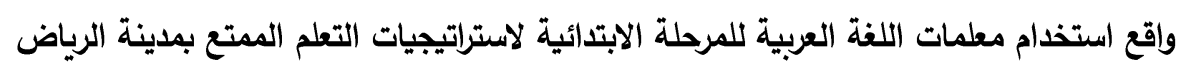

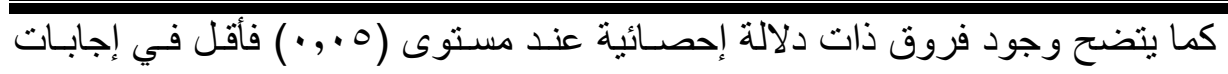
أفر اد عينة الدراسة حـول (وسـائل وتقنيـات اسـتر اتيجيات التعلم الممتع، و أسـاليب تقويم استراتيجيات التعلم المثتع) باختلاف متغير العمر. (ب) الفروق باختلاف منغير المستوى التعليمي: للتعرف ما إذا كانت هناك فروق ذات دلالة إحصائية بين منوسط إجابات أفر اد عينة الدراسة طبقًا لاختلاف متغير المستوى التعليمي؛ تم استخدام اختبار "ت" Independent Sample T-test، لتوضيح دلالة الفروق بين إجابات أفراد

$$
\text { عينة الدراسة، وجاءت النتائج كما يوضحها الجدول الآتي: }
$$

جدول (Y) نتائج اختبار "ت": Independent Sample T-test للفروق بين إجابات أفراد عينة الدراسة طبقًا إلى اختلاف متغير المستوى التعليمي

\begin{tabular}{|c|c|c|c|c|c|c|}
\hline الدلالة & قيمة ت & المعياري & المتوسط & العدد & النوع & المحور \\
\hline \multirow[b]{2}{*}{ •, VYT } & \multirow[b]{2}{*}{ - } & $\cdot, Y \cdot \varepsilon$ & $\cdot, \mathrm{VH}$ & $17 \varepsilon$ & بكالوريوس & \multirow[b]{2}{*}{ طرق التعلم المتع } \\
\hline & & •, זצ. & . V7 & $1 \varepsilon$ & ماجستير & \\
\hline \multirow{2}{*}{$\cdot, .79$} & \multirow{2}{*}{1,909} & $\cdot, Y \backslash V$ & $\cdot, 74$ & $17 \varepsilon$ & بكالوريوس & \multirow{2}{*}{ وسائل التعلم المتع } \\
\hline & & $\cdot, r 19$ & $\cdot, \mathrm{\vee} \wedge$ & $1 \varepsilon$ & ماجستير & \\
\hline \multirow{2}{*}{$\cdot, 1 \leqslant r$} & \multirow{2}{*}{$1,0 \leq 7$ - } & $\cdot, Y \wedge \vee$ & $\cdot, 01$ & $17 \varepsilon$ & بكالوريوس & \multirow{2}{*}{ أننطة التعلم الممتع } \\
\hline & & $\cdot, r \vee q$ & $\cdot, \mathrm{VI}$ & $1 \varepsilon$ & ماجستير & \\
\hline \multirow{2}{*}{$\cdot, 791$} & \multirow{2}{*}{ •, rq०_ } & $\cdot, r \cdot 1$ & $\cdot, \wedge 7$ & $17 \varepsilon$ & بكالوريوس & \multirow{2}{*}{ أساليب تقويم التعلم الممتع } \\
\hline & &., 191 & $\cdot, \wedge \wedge$ & $1 \varepsilon$ & ماجستير & \\
\hline \multirow{2}{*}{$\cdot, \wedge 10$} & \multirow{2}{*}{ • YTH_ } & $\cdot, Y \cdot Y$ & $\cdot, 77$ & $17 \varepsilon$ & بكالوريوس & \multirow{2}{*}{ معوقات استخدام التعلم } \\
\hline & & $\cdot,(19)$ & $\cdot, 7 \Lambda$ & $1 \leq$ & ماجستير & \\
\hline
\end{tabular}

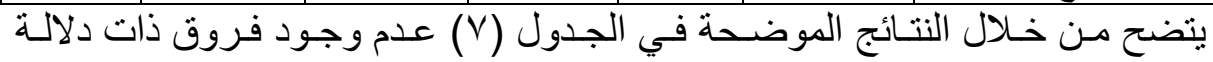
إحصائية عند مستوى (0. . ·) فأقلّ في إجابات أفراد عينة الدراسة حول (طرق وأساليب التعلم الممتع، ووسائل وتقنيات اسـتر اتيجيات التعلم الممتع، و أنشـة تنفيذ استر اتيجيات 
أ.م.د/ وفاء بنت عايض سعد الحارثي

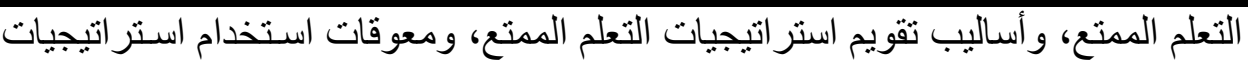
التعلم الممتع) باختلاف متغير المستوى التعليمي. (ج) الفروق باختلاف متغير عدد سنوات الخبرة:

للتعرف ما إذا كانت هناك فروف ذات دلالة إحصائية في إجابات أفراد عينة الدراسـة

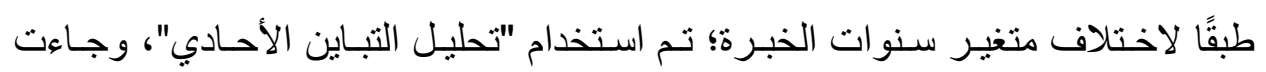
النتائج كما يوضحها لالجدول الآتي:

الجدول (^) نتائج " تحليل التباين الأحادي " (One Way ANOVA) للفروق في إجابات أفر اد عينة الدراسة طبقًا إلى اختلاف سنوات الخبرة

\begin{tabular}{|c|c|c|c|c|c|c|}
\hline |الإحصائية & قيمة ف & متوسط المربعات & | & مربعات & مصدر التباين & المحور \\
\hline \multirow{3}{*}{$\cdot, 70}$. & \multirow{3}{*}{$\cdot, 0 \leqslant \Lambda$} & $\cdot, \cdot Y \leq$ & $r$ & $\cdot, \cdot V Y$ & بين المجموعات & \multirow{3}{*}{ طرق و أساليب التعلم } \\
\hline & & $\cdot, \cdot \leq \varepsilon$ & $1 V \varepsilon$ & $V, T Y Y$ & داخل المجمو عات & \\
\hline & & & IVV & $V, 79 \varepsilon$ & المجموع & \\
\hline \multirow{3}{*}{$\cdot, \cdot 1 \pi$} & \multirow{3}{*}{$* r, V \backslash 0$} & $\cdot, \mid 1 V 1$ & $r$ &., $01 \varepsilon$ & بين المجموعات & \multirow{3}{*}{ 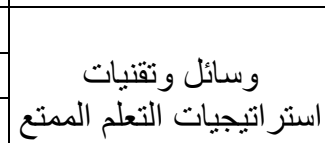 } \\
\hline & & $\cdot, \cdot \leq 7$ & $1 V \varepsilon$ & $\Lambda, \cdot r q$ & داخل المجمو عات & \\
\hline & & & IVV & $\Lambda, 0 \leqslant \leqslant$ & المجموع & \\
\hline \multirow{3}{*}{$\cdot$, , } & \multirow{3}{*}{$1, \cdot r}$. & $\cdot, \cdot \wedge 7$ & $r$ & $\cdot, Y O V$ & بين المجمو عات & \multirow{3}{*}{ أنشطة تنفيذ استر اتيجيات المعلم المتع } \\
\hline & & $\cdot, \cdot \wedge r$ & $I V \varepsilon$ & $1 \leqslant, \varepsilon \leqslant \wedge$ & داخل المجمو عات & \\
\hline & & & IVV & $1 \leq, V \cdot 0$ & المجموع & \\
\hline \multirow{3}{*}{$\cdot, \varepsilon \cdot r$} & \multirow{3}{*}{$\cdot, 9 \wedge$. } & $\cdot, \cdot \varepsilon \cdot$ & $r$ & $\cdot, 119$ & بين المجموعات & \multirow{3}{*}{ |أساليب تقويم استر اتيجيات التعلم الممتع } \\
\hline & & $\cdot, \cdot \varepsilon \cdot$ & IVE & $v, .10$ & داخل المجمو عات & \\
\hline & & & $I V V$ & $V, 1 T \varepsilon$ & المجموع & \\
\hline \multirow{3}{*}{$\cdot, \cdot r q$} & \multirow{3}{*}{$* r, I \vee r$} & $\cdot, 1$ To & $r$ & $\cdot, \varepsilon \cdot\rceil$ & بين المجموعات & \multirow{3}{*}{ |ستر اتيجيات التعلم المثتع استخدات } \\
\hline & & $\cdot, \cdot \leq r$ & $I V \varepsilon$ & $V, \varepsilon Y$. & داخل المجمو عات & \\
\hline & & & IVV & $V, \wedge$ YO & المجموع & \\
\hline
\end{tabular}

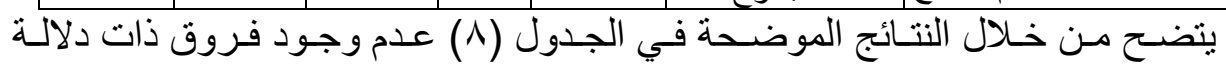
إحصائية عند مستوى (0. . . ) فأقل في إجابات أفر اد عينة الدراسة حول (طرق وأساليب التعلم الممتع، و أنشـطة تنفيذ اسـتر اتيجيات التعلم الممتعع، وأسـاليب تقويم استر اتيجيات التعلم الممتع) باختلاف متغير سنوات الخبرة.

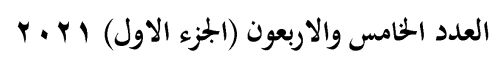

مجلة كلية التربية- جامعة عين شمس 
واقع استخدام معلمات اللغة العربية للمرحلة الابتائية لاستراتيجيات التعلم الممتع بمدينة الرياض

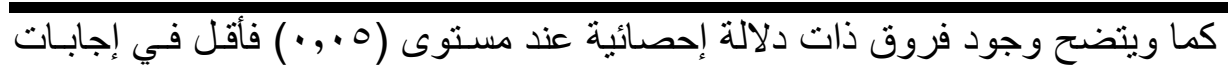
أفراد عينة الدراسة حول (وسائل وتقنيات استر اتيجيات التعلم الممتع، ومعوقـات استخدام استر اتيجيات التعلم الممتع) باختلاف متغير سنوات الخبرة. (د) الفروق باختلاف متغير عدد الدورات التدريبية : للتعرف ما إذا كانت هناللك فروق ذات دلالة إحصائية في إجابات أفر اد عينـة الدراسـة

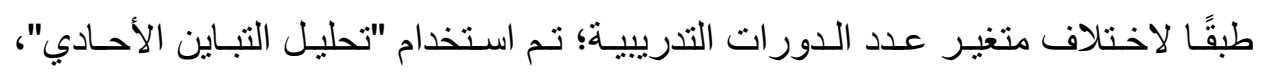
وجاءت النتائج كما يوضحها الجدول التالي:

جدول (9) نتائج " تحليل التباين الأحادي " (One Way ANOVA) للفروق في إجابات أفراد عينة الدر اسة طبقًا إلى اختلاف عدد الدورات لتحات التدرييية

\begin{tabular}{|c|c|c|c|c|c|c|}
\hline | الإحصائية |لالة & قيمة ف & متوسط المربعات & - ل الحرية & 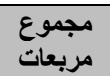 & مصدر التباين & المحور \\
\hline \multirow{3}{*}{$\cdot, 99$} & \multirow{3}{*}{$r, 101$} & $\cdot, .94$ & $r$ & $\cdot$, YVO & بين المجموعات & \multirow{3}{*}{ طرق و أساليب التعلم الممتع } \\
\hline & & $\cdot, \cdot \leq r$ & IV & $V, \varepsilon 19$ & داخل المجمو عات & \\
\hline & & & $I V V$ & $V, 79 \leq$ & المجموع & \\
\hline \multirow{3}{*}{$\cdot, 9 \vee 9$} & \multirow{3}{*}{$\cdot, .70$} & $\cdot, \ldots r$ & $r$ & $\cdot, \cdot 1 \cdot$ & بين المجموعات & \multirow{3}{*}{ وسائل وتقنيات استر اتيجيات التعلم } \\
\hline & & $\cdot, \cdot \leq 9$ & IV & $\wedge, 0 r \leq$ & داخل المجمو عات & \\
\hline & & & $I V V$ & $1,0 \leqslant \leqslant$ & المجموع & \\
\hline \multirow{3}{*}{$\cdot, 711$} & \multirow{3}{*}{$\cdot, 7 \cdot 1$} &., .01 & $r$ & $\cdot, 104$ & بين المجمو عات & \multirow{3}{*}{ أنشطة تتفيذ استر اتيجيات التعلم الممتع } \\
\hline & & $\cdot, \wedge \varepsilon$ & IV & $1 \varepsilon, 00 Y$ & داخل المجمو عات & \\
\hline & & & $I V V$ & $1 \leq, V \cdot 0$ & المجموع & \\
\hline \multirow{3}{*}{$\cdot, Y V I$} & \multirow{3}{*}{$1, \pi 10$} &., .04 & $r$ &., 101 & بين المجمو عات & \multirow{3}{*}{ أساليب تقويم استر اتيجيات التعلم الممتع } \\
\hline & & $\cdot, \cdot \varepsilon \cdot$ & TV & $7,9 \vee 7$ & داخل المجمو عات & \\
\hline & & & IVV & $V, 1 \Gamma \leq$ & المجموع & \\
\hline \multirow{3}{*}{$\cdot, \sum \Psi 1$} & \multirow{3}{*}{ • } & $\cdot, \cdot \leq 1$ & $r$ & $\cdot, I K r$ & بين المجموعات & \multirow{3}{*}{ معوقات استخدام استر اتيجيات التعلم } \\
\hline & & $\cdot, \cdot \leq \varepsilon$ & IV & $V, V \cdot r$ & داخل المجمو عات & \\
\hline & & & IVV & $V, \Lambda$ Y O & المجموع & \\
\hline
\end{tabular}

يتضح من خلال النتائج الموضحة أعلاه عدم وجود فروق ذات دلالة إحصائية عند مستوى (0., ·) فأقل في إجابات أفراد عينة الدراسة حول (طرق وأساليب التعلم الممتع، وسائل وتقنيات استراتيجيات التعلم الممتع، أنشطة تنفيذ استراتيجيات التعلم الممتع، أساليب تقويم استراتيجيات التعلم الممتع، معوقات استخدام استراتيجيات التعلم الممتع) باختلاف متغير عدد الدورات التدريبية. 


\section{أ.م.د// وفاء بنت عايض سعد الحارثي}

التوصياث:

- زيادة وعي معلمات اللغة العربية بالأسس النظرية للتعلم الممتع من أجل الاستخدام الصحيح لاستر اتيجياته وذلك من خلال الندوات، و الدور ات، و النشر ات التوضيحية . - إعداد دليل للمعلمة، يوضح فيه استر اتيجيات التعلم الممتع المناسبة لتلميذات المرحلة الابتدائية، وطريقة استخدامها في تعليم اللغة العربية. - - توفير البيئة التربوية الداعمة للمعلمات لاستخدام استراتيجيات التعلم الممتع، مثل المباني المدرسية المجهزة بالتقنيات الحديثة - زيادة الدعم المالي والمادي لمدارس المرحلة الابتدائية للانتقال من التعليم التقليدي إلى التعلم من أجل المتعة.

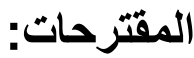

- إجراء در اسة للكثف عن فاعلية برنامج تدريبي لتنمية أداء معلمات اللغة العربية لاستخدام استر اتيجيات التعلم الممتع.

- إجراء دراسات مماتلة على عينة من المعلمين، أو المعلمات في المراحل الأخرى، وفي المدن الأخرى من المملكة العربية السعودية. - إجراء دراسة للكثف عن فاعلية برنامج تعليمي قائم على التعلم الممتع لتنمية مهار ات اللغة العربية لدى الطلاب. 
واقع استخدام معلمات اللغة العربية للمرحلة الابتدائية لاستراتيجيات التعلم الممتع بمدينة الرياض

\section{المراجع}

البركاتي، نيفين حمزة (Y V V V). برنامج تدريبي مقترح قائم على استراتيجيات التعلم المثنع

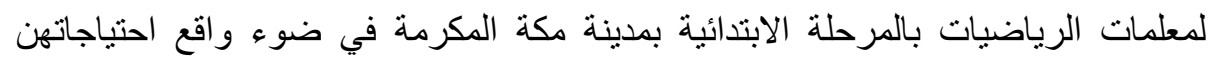

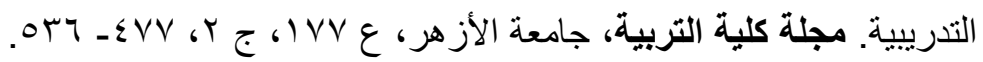
حمدان، صلاح الدين (1) (Y). استراتيجيات التدريس الحديثة مدخل تطبيقي. دار المسيرة لمنشر والتوزيع: عمان.

حمزة، محدد (•(ب). مفاهيم أساسية في الرياضيات الأعداد والعمليات عليها وأساليب تدريسها، عمان، دار الفكر ناشرون وموزعون. الجغيمان، عبد الله (ץ . ץץ). هل زرت هذا الصف: عندها ستعرف منعة التعلم و التعليم، المعرفة

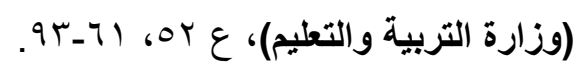

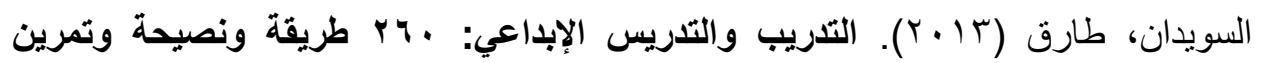
للإبداع في التدريب التدريس. (طه)، الكويت: شركة الإبداع الفكري.

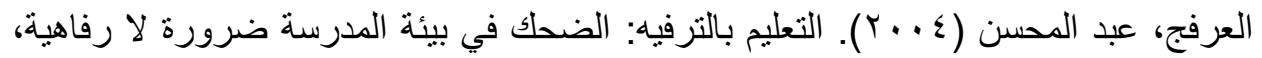

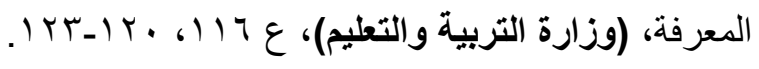

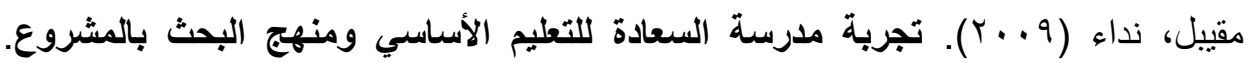

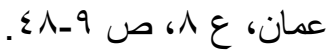
محمود، خالد (T ( • Y). هل يفتح مفهوم التعلم للمتعة آفاقا جديدة في ميدان التربية؟ متاح على

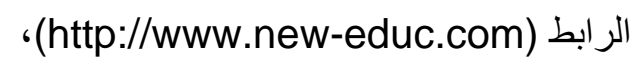

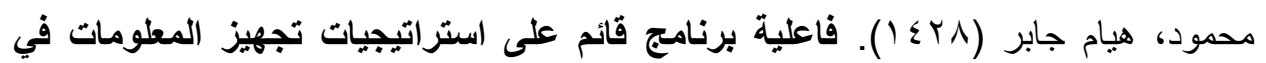
تنمية التحصيل النحوي والأداء النحوي في القراءة والكتابة لاى تلاميذ مرحلة التعليم الأساسي. رسالة دكتور اه غير منشورة، جامعة الزقازيق، كلية التربية النوعية، قسم العلوم التربوية و النفسية.

النصار، صالح بن عبد العزيز (•؟؟ (). تقويم أدوار معلمين اللغة العربية في المرحلتين

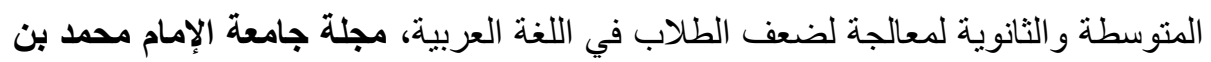


أ.م.د/ وفاء بنت عايض سعد الحارثي

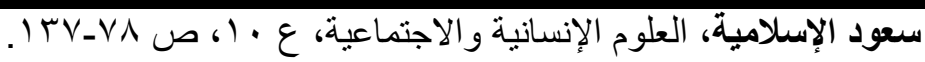

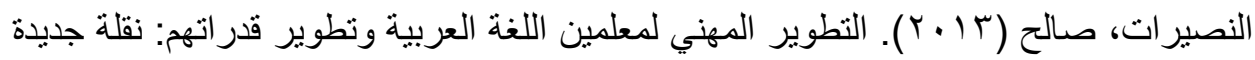
في ظل النعليم المبني على المعايير، ورقة عمل مقدمة إلى المؤتمر الدولي الثاني للغة

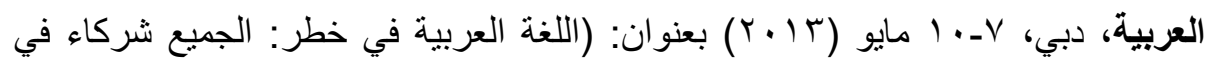

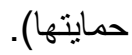

الهويدي، زيد († +. ץ). أساليب واستراتيجيات تدريس الرياضيات، العين، دار الكتاب الجامعي.

https://www.moe.gov.sa/ar/Pages/vision2030.aspx موقع وزارة التعليم

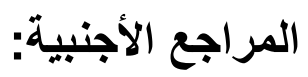

Anggoro, S., \& Sholehuddin, M. (2017). Influence of joyful learning on elementary school students' attitudes toward science. Journal of Physics: Conf.,812 (1),1-6.

Barab, S., Thomas, S., Dodge, T., Carteaux, R., Tuzun, H. (2005)

Making Learning Fun: Quest Atlantis, A Game Without Guns, ETR\&D, (53) 1, P 86- 107.

Cox, J. (2016). Ways to Make Learning Fun Again, http://www.teachhub.com/5-ways-make-learning-fun-again.

Cox, J. (2018). How to Make Learning Fun 10 Fun and Exciting New Ideas to Try Today https://www.thoughtco.com/how-tomake-learning-fun-2081740

Falk, J. H. (2006). An identity-centered approach to understanding museum learning. Curator: The Museum Journal, v.49, (2), $p$ 151-166.

Fencl, J. (2014). Fun and Creative Unit Assessment Ideas for All

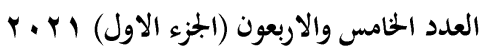

مجلة كلية التربية- جامعة عين شمس 
واقع استخدام معلمات اللغة العربية للمرحلة الابتدائية لاستراتيجيات التعلم المتع بمدينة الرياض

Students in Physical Education, Journal of Physical Education, Recreation and Dance, v.85, p 16-21.

Ford, M., Opitz, M., \&Emeritus, M. (2015). Helping young children discover the joy of learning. Human Factor Studies, 21, p 27- 42. Khoirul, A, Rohmy, H. (2016). Evaluating Integrated Task Based Activities and Computer Assisted Language Learning. (CAL). English Language Teaching, v.9, (4), p 119-127.

Lawrence, D. (2017). Towards a fun and playful model for young children's foreign language learning. Master Thesis in

Education, Department of Education, University of Jyväskylä.

Rambli, D., Macha, W., Suliman, S. (2013). Fun Learning with AR Alphabet Book for Preschool Children. Procedia Computer Science (25), p $211-219$.

Schattner, p. (2015). The Case for "Story-Driven" Biology

Education, Journal of Biological Education, v.49, (3), p 334447.

Packer, J. (2006). Learning for Fun: The Unique Contribution of Educational Leisure Experiences. Curator: The Museum Journal, v.49, (3), p 329-344.

Wang, J. (2017). The joy of learning. What it is and how to achieve it. National Institute of Education, Nanyang Technological University. 